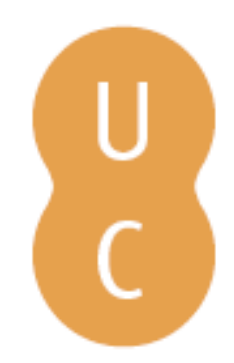

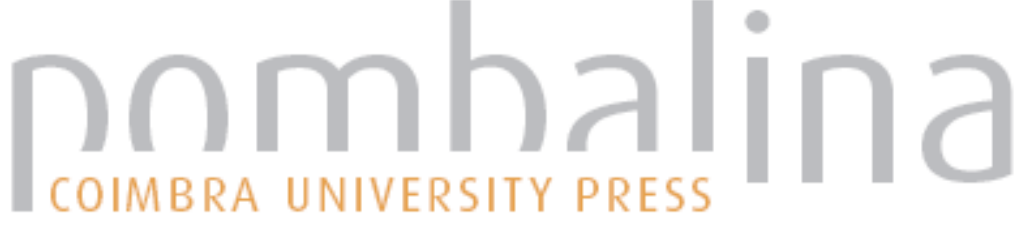

\section{Investigação biológica de parentesco}

Autor(es): Dario, Paulo; Geada, Helena de Seabra

Publicado por: Imprensa da Universidade de Coimbra

URL

persistente:

URI:http://hdl.handle.net/10316.2/38505

DOI:

DOI:http://dx.doi.org/10.14195/978-989-26-0957-7_4

Accessed : $\quad$ 26-Apr-2023 08:12:18

A navegação consulta e descarregamento dos títulos inseridos nas Bibliotecas Digitais UC Digitalis, UC Pombalina e UC Impactum, pressupõem a aceitação plena e sem reservas dos Termos e Condições de Uso destas Bibliotecas Digitais, disponíveis em https://digitalis.uc.pt/pt-pt/termos.

Conforme exposto nos referidos Termos e Condições de Uso, o descarregamento de títulos de acesso restrito requer uma licença válida de autorização devendo o utilizador aceder ao(s) documento(s) a partir de um endereço de IP da instituição detentora da supramencionada licença.

Ao utilizador é apenas permitido o descarregamento para uso pessoal, pelo que o emprego do(s) título(s) descarregado(s) para outro fim, designadamente comercial, carece de autorização do respetivo autor ou editor da obra.

Na medida em que todas as obras da UC Digitalis se encontram protegidas pelo Código do Direito de Autor e Direitos Conexos e demais legislação aplicável, toda a cópia, parcial ou total, deste documento, nos casos em que é legalmente admitida, deverá conter ou fazer-se acompanhar por este aviso.

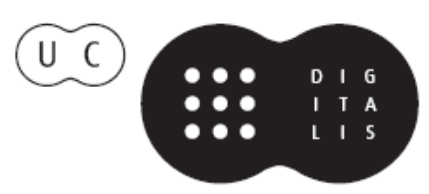




\section{PRINCÍPIOS}

\section{DE GENÉTICA}

\section{FORENSE}

FRANCISCO CORTE-REAL DUARTE NUNO VIEIRA

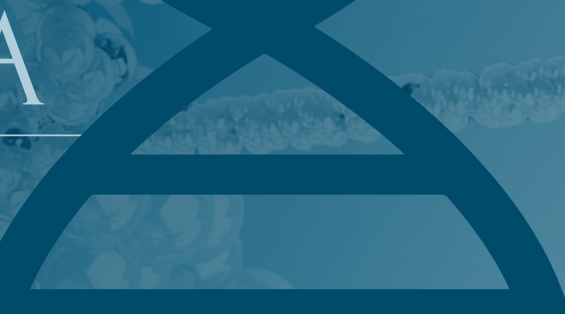

c)
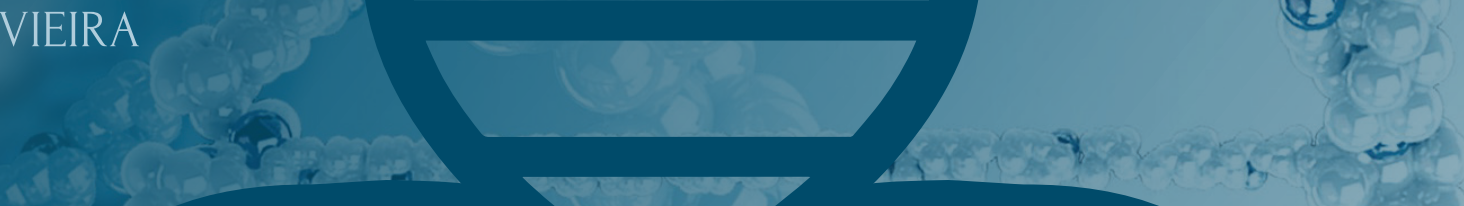

(4)

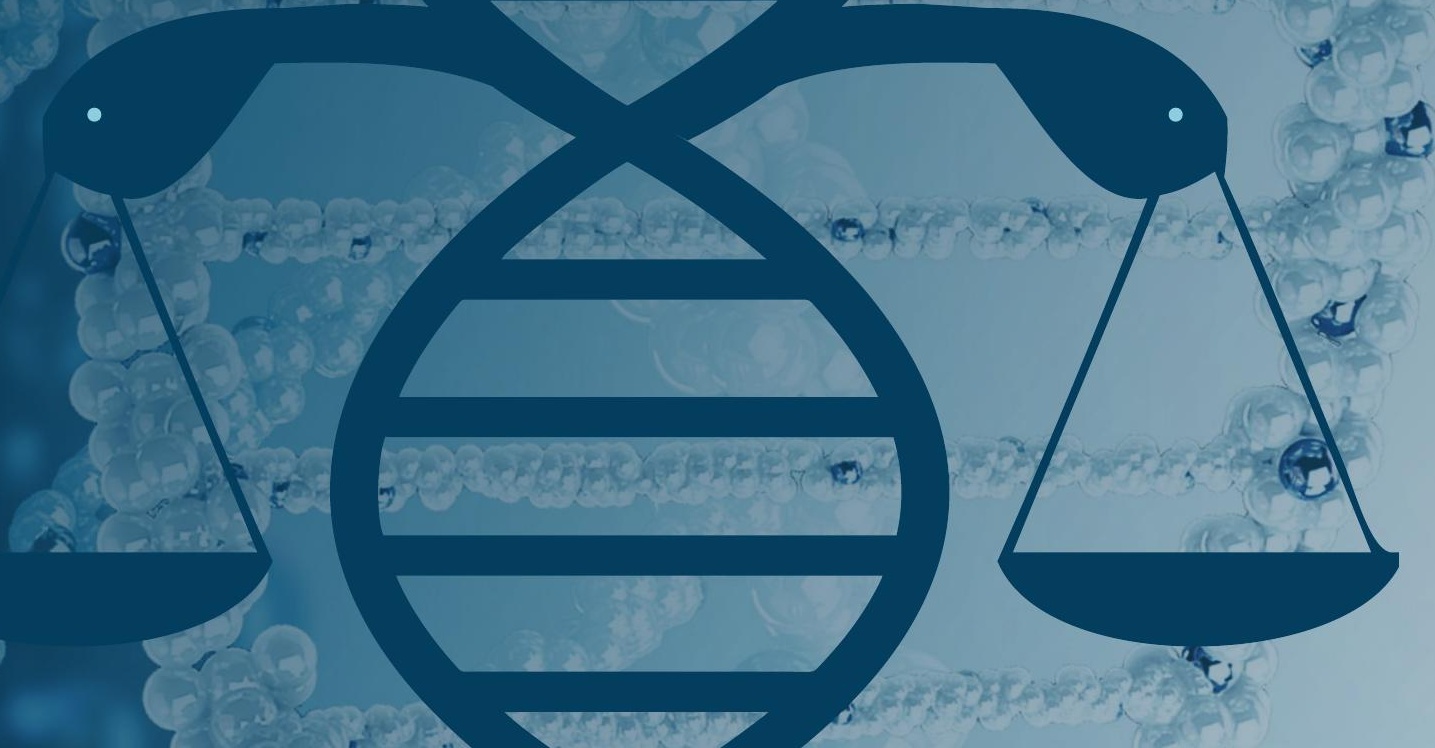

min $2(5)$

Exar. 
Capítulo 4

INVESTIGAÇÃO BIOLÓGICA DE PARENTESCO

\section{Paulo Dario Helena de Seabra Geada}

Delegação do Sul do Instituto Nacional de Medicina Legal e Ciências Forenses, I. P. CENCIFOR - Centro de Ciências Forenses

Faculdade de Medicina da Universidade de Lisboa DOI | HTTP://DX.DOI.ORG/10.14195/978-989-26-0957-7_4 


\section{RESUMO}

Com a reforma de 1977 do Código Civil Português, a investigação de paternidade passou a ser livremente admitida, sendo que, nas ações de filiação, os exames de sangue ou outros métodos cientificamente comprovados, como exames de outros materiais biológicos, passaram a ser admitidos como meio de prova neste tipo de investigações. Atualmente, nos Laboratórios de Genética Forense, a investigação biológica de paternidade é realizada em amostras de saliva recolhidas com zaragatoas bucais ou amostras de sangue obtidas por punção digital, e analisadas, essencialmente, com recurso ao estudo de STRs autossómicos. Estes estudos têm por base o trio pretenso pai/mãe/filho(a), sem prejuízo de outro tipo de investigações que podem ser solicitadas aos Laboratórios de Genética Forense, tais como, investigações com dois ou mais pretensos pais ou com dois ou mais irmãos. Mas os casos complexos são determinados por investigações de parentesco incompletas, normalmente na ausência do pretenso pai que se pretende investigar. Neste caso, estas investigações devem ser efetuadas com recurso ao perfil genético dos pretensos familiares paternos, tais como, pais, irmãos ou filhos do pretenso pai. Estas investigações podem ser complementadas com outros marcadores genéticos, nomeadamente, aumentando o número de STRs autossómicos estudados com outros sistemas multiplex utilizados na prática forense, ou mesmo recorrendo ao estudo de Y-STRs para determinação da linha paterna, de ADN mitocondrial para estudo da linha materna ou, em casos especiais, estudo de STRs do cromossoma X. Mas as situações da prática forense podem ser bastante mais complexas, sendo necessárias investigações com marcadores bialélicos, como SNPs ou INDELs, para complementar o estudo de STRs, sobretudo, em casos de amostras degradadas. Por outro lado, a implementação da acreditação nos Laboratórios de Genética Forense teve início com a implementação de um Sistema de Gestão da Qualidade (SGQ), baseado na norma ISO/ IEC 17025, garantindo, assim, a qualidade das perícias de investigação biológica de parentesco realizadas.

\section{PALAVRAS-CHAVE}

Investigação biológica de parentesco; polimorfismos de ADN.

\section{ABSTRACT}

With the 1977 reform of the Portuguese Civil Code, paternity became freely admitted, and that the actions of affiliation, blood tests or other scientifically proven methods such as examinations of other biological materials, have been admitted as evidence in this type of investigations. Currently, at the Laboratories of Forensic Genetics, biological paternity is carried in saliva samples collected with buccal swabs or blood samples obtained by finger prick and analyzed essentially using autosomal STRs. These studies are based on the alleged father/mother/son(daughter) or other types of research that can be applied to Forensic Genetics Laboratories, such as investigations with two or more alleged fathers or with two or more siblings. But complex cases are determined by kinship incomplete investigations, usually in the absence of the alleged father. In this case, these investigations should be carried out using the genetic profile of the alleged paternal relatives, such as parents, siblings or children of the alleged father. These investigations can be complemented with other genetic markers, namely increasing the number of studied autosomal STRs with other multiplex systems used in forensics, or by studying the Y-STRs for determining the parental lineage, the mitochondrial DNA for the study of maternal lineage or, in special cases, the study of X-chromosome STRs. But the circumstances in forensics can be quite complex, being necessary studies with biallelic markers, such as SNPs and INDELs, to complement the study of STRs, especially in cases of degraded samples. On the other hand, the implementation of accreditation in Forensic Genetics Laboratories began with the implementation of a Quality Management System (QMS) based on ISO/IEC 17025, thus ensuring the quality of the biological kinship analysis performed.

\section{KEYWORDS}

Biological kinship analysis; DNA polymorphisms. 


\section{INTRODUÇÃO}

Nas últimas décadas, as Ciências Forenses têm sido objeto de significativa valoração devido, nomeadamente, à introdução de novas tecnologias e de aparelhagem de análise mais sofisticada. Quanto à Genética Forense, não só este ramo teve um enorme desenvolvimento, como, também, nos últimos anos, este desenvolvimento sofreu uma aceleração ímpar relativamente a qualquer outro ramo da atividade médico-legal, pela introdução da tecnologia do ADN. A contribuição dos Laboratórios de Genética Forense, como auxiliares da Justiça, para a resolução de problemas de âmbito social adquire, assim, uma enorme relevância.

No âmbito da Genética Forense, os exames têm normalmente um único objetivo — o estudo do perfil genético dos indivíduos, através das amostras colhidas e enviadas ao Laboratório. O problema da identificação dos indivíduos será, para o Laboratório de Genética Forense, um dos objetivos principais. As características genéticas são únicas, no seu conjunto, para cada indivíduo, caracterizando, deste modo, a sua individualidade biológica.

Karl Landsteiner, ao descobrir o sistema ABO e as suas características hereditárias, profetizou, no início do século passado, que "um dia os grupos sanguíneos permitiriam identificar os homens tão bem como as impressões digitais" (Landsteiner et al., 1928). Landsteiner refletiu, assim, sobre a possibilidade do uso destes marcadores para fins forenses, tendo esta descoberta servido de base para a realização de perícias de investigação da paternidade, até meados dos anos 80 . Com base nestes trabalhos, Landsteiner viria a receber 0 Prémio Nobel da Medicina, em 1930.
Também, no final do século passado, se assistiu à aplicação das chamadas "impressões digitais genéticas" (DNA fingerprinting) na identificação biológica. A primeira perícia de investigação genética de parentesco biológico com recurso a marcadores moleculares (VNTRs - Variable Number Tandem Repeats) foi realizada, em 1985, num caso de imigração de indivíduos do Gana, que pretendiam obter um visto de reunião familiar, existindo dúvidas sobre a veracidade das relações de parentesco com os alegados parentes residentes no Reino Unido. Alec Jeffreys, da Universidade de Leicester, provou a veracidade destas relações (Jeffreys et al., 1985) e demostrou, também, inequivocamente, o grande poder do ADN na identificação genética de indivíduos.

A investigação em Genética Forense aplica as tecnologias de Biologia Molecular ao estudo de polimorfismos de loci de ADN com interesse forense. Este estudo, de relevância médico-legal integra a genética populacional e a identificação biológica que se desenvolve principalmente nas seguintes vertentes: a) investigação biológica de filiação, debruçando-se em particular sobre as investigações de paternidade e de maternidade; b) investigação biológica de parentesco, que engloba, entre outros, também os estudos de casos de imigração; c) identificação biológica de desconhecidos, onde se insere a identificação em desastres de massa e d) investigação criminal biológica. Perspetivam-se, atualmente, outros campos de interesse da investigação forense, como sejam, as investigações históricas e o campo fascinante da Arqueologia Forense.

A individualidade biológica constitui, assim, a base fundamental da perícia de identificação biológica e é, atualmente, efetuada através dos 
polimorfismos de loci de ADN, nomeadamente, STRs autossómicos, STRs do cromossoma $Y$ e STRs do cromossoma X. O ADN mitocondrial e a introdução do estudo de SNPs na rotina e na resolução de casos complexos são outras das metodologias utilizadas em Genética Forense.

Como já referido em capítulos anteriores, os STRs autossómicos encontram-se abundantemente distribuídos no genoma humano, sendo caracterizados por pequenas repetições em sequência, repetições estas essencialmente de 2 a 7 pares de bases (pb) de comprimento. A maioria dos loci STR autossómicos usados na identificação humana apresenta repetições de 4 pb, e alguns de $5 \mathrm{pb}$, com alelos compreendidos entre os 100 e os $350 \mathrm{pb}$. Os STRs tetraméricos e pentaméricos utilizados são sistemas com grande poder de discriminação e especificidade para a análise da variabilidade humana.

Recorre-se, contudo, à utilização de sistemas multiplex para o estudo destes loci, utilizando os multiplex PowerPlex® 16 (/HS) System e/ou AmpFeSTR® Identifiler ${ }^{\circledR}$ (/Direct/Plus). Estes multiplex comerciais, para além dos 13 loci do sistema CODIS, permitem no seu conjunto o estudo de outros quatro STRs: D2S1338, D19S433, Penta E e Penta D. São estes 17 loci os atualmente mais utilizados nas perícias de Genética Forense, sem prejuízo de outros sistemas que os diferentes Laboratórios disponham para a análise de rotina ou de casos complexos, como, por exemplo, outros marcadores contidos em diferentes sistemas multiplex como o AmpFeSTR® NGM ${ }^{\mathrm{TM}}$ ou o PowerPlex® ES.

O estudo dos loci STR dos diferentes grupos populacionais constitui um complemento das perícias forenses e, assim, uma das atribuições dos Laboratórios Forenses. Os polimorfismos dos microssatélites, para além de caracterizarem o indivíduo do ponto de vista da sua individualidade biológica, permitem, também, o estudo das populações. Este estudo populacional é de importância fundamental para todas as investigações na área da Genética Forense, pois as conclusões destas perícias são efetuadas com base em cálculos estatísticos, para os quais é necessário o conhecimento da genética populacional.

O estudo da genética populacional revestir-se-á, assim, de aspetos essenciais não só no âmbito dos exames periciais, mas, também, no da caracterização dos diversos grupos populacionais que, atualmente, integram a população de indivíduos e/ou amostras presentes aos diversos Laboratórios Forenses.

\section{ESTABELECIMENTO DA FILIAÇÃO}

Segundo o Código Civil Português, de 1977, o estabelecimento da filiação assenta na diferença entre estabelecimento da maternidade e estabelecimento da paternidade: "O estabelecimento da filiação relativamente à mãe, resulta do próprio facto do nascimento, enquanto a paternidade presume-se em relação ao marido da mãe e, nos casos da filiação fora do casamento, estabelece-se pelo reconhecimento" (art. ${ }^{\circ} 1796^{\circ}$. - Estabelecimento da filiação).

Tanto a maternidade como a paternidade são factos biológicos que carecem de vínculo jurídico. Contudo, estes dois factos biológicos têm um modo diferente de ser provados. No caso da mãe, a filiação resulta do facto do nascimento, enquanto para o pai não se pode provar o seu 
envolvimento biológico, como se prova a maternidade (Oliveira, 1983). No estabelecimento da paternidade "presume-se que o filho nascido ou concebido na constância do matrimónio da mãe tem como pai o marido" (art. ${ }^{\circ} 1826^{\circ}$ - Presunção de paternidade).

Existem, contudo, situações, em que o Tribunal ordena um exame de investigação de paternidade para verificar se é ou não possível, excluir o marido da mãe, da paternidade biológica da criança. Mas as situações mais comuns que levam a uma averiguação da paternidade são aquelas nas quais a mulher atribui a paternidade do seu filho a um indivíduo a quem, à face da lei, não é aplicável tal presunção. Este facto passa-se em relação à mulher solteira, casada ou viúva, pois segundo o Código Civil, "o reconhecimento do filho nascido ou concebido fora do matrimónio efetua-se por perfilhação ou decisão judicial em ação de investigação" (art. ${ }^{\circ}$ $1847^{\circ}$ - Formas de reconhecimento).

Conclui-se que deve ser declarado pai do indivíduo nascido ou concebido fora do casamento, quem for o seu pai biológico. Quanto à paternidade desconhecida, "sempre que seja lavrado registo de nascimento de menor apenas com a maternidade estabelecida, deve o funcionário remeter ao Tribunal certidão integral do registo, a fim de se averiguar oficiosamente a identidade do pai" (art. . 1864 - Paternidade desconhecida).

Com a reforma de 1977 do Código Civil, desapareceram os entraves à investigação de paternidade, que passou a ser livremente admitida. Segundo o art. $1801^{\circ}$ - "nas acções de filiação são admitidos como meios de prova os exames de sangue ou quaisquer outros métodos cientificamente comprovados".
Segundo o enunciado do art. $^{\circ} 1871^{\circ}$ do Código Civil, a filiação biológica prova-se, de modo indireto, pela prova de exclusividade das relações sexuais entre o investigado e a mãe do investigante, no período legal da conceção, bem como por meio de presunções legais. A prova por presunções faz-se através da prova dos factos como tal legalmente considerados.

Mas o Assento $n^{\circ} 4 / 83$ refere os dois factos constitutivos da paternidade biológica: a) a existência de relações sexuais entre a mãe do investigante e o pretenso pai durante o período legal da conceção; b) a fidelidade da mãe do investigante ao pretenso pai durante o mesmo período. Caso se averigue, por exemplo, que a mãe do menor manteve relações sexuais com dois indivíduos, os exames de sangue serão muito úteis e necessários, pois um dos indivíduos será necessariamente excluído, enquanto o outro apresentará um elevado grau de probabilidade de paternidade. Como se verifica, para os exames de investigação de paternidade é irrelevante a prova da fidelidade da mãe. Esta prova não se revela necessária para a obtenção de um resultado concreto, quer seja de exclusão, quer seja de não exclusão (Geada et al., 1990-91).

Nos casos de possível ocorrência de relações sexuais com mais de um indivíduo, os exames de sangue terão, como referido, uma função útil a desempenhar, pois a conclusão relativamente à paternidade não será determinada pelo exame que acuse o maior grau de probabilidade, mas sim pela exclusão dos indivíduos falsamente implicados, caso estes se apresentem a exame, e a obtenção de um valor de probabilidade de paternidade elevado para o indivíduo não excluído, não se admitindo valores relativos de probabilidade de paternidade. 
Como refere o Acórdão do Supremo Tribunal de Justiça de 26 de Junho de 1991, "os exames de sangue não constituem uma presunção de paternidade, pois tendem à prova directa da paternidade biológica". A não exigência deste tipo de provas em todas as ações de investigação de paternidade pode levar a que muitas dessas ações não sejam conclusivas, por não se apresentar uma prova tão específica como a prova científica (Geada et al., 1990-91).

\section{INVESTIGAÇÃO GENÉTICA DE PARENTESCO}

Os estudos de investigação genética de parentesco baseiam-se, essencialmente, em estudos de investigações de paternidade, investigações de maternidade, estudo de pretensos irmãos, estudo com pretensos avós paternos, assim como estudos envolvendo outros familiares. Estes casos podem, muitas vezes, configurar situações complexas e especiais de estabelecimento biológico de parentesco.

Os casos mais comuns, solicitados aos Laboratórios de Genética Forense, configuram investigações de paternidade efetuadas com a presença do trio pretenso pai/mãe/filho(a), embora estes estudos possam ser realizados na ausência do pretenso pai (p.pai), recorrendo a familiares da linha paterna.

Este tipo de investigação pode ser solicitada pelos Tribunais e pelas Forças de Segurança (PJ, PSP e GNR), diretamente ao Diretor da respetiva Delegação do Instituto Nacional de Medicina Legal, ou aos Coordenadores dos Gabinetes
Médico-Legais, que procedem à colheita e envio das amostras à respetiva Delegação, como mais adiante será explicitado.

Outra das situações que começa a ter grande relevância na nossa Sociedade, refere os pedidos efetuados particularmente, quer no âmbito da investigação de paternidade e/ou de maternidade, quer no estabelecimento de parentesco biológico. Estes casos, solicitados ao Presidente da Instituição, sedeada em Coimbra, são devidamente encaminhados para o Gabinete de Assessoria Jurídica, que fará a apreciação da matéria de facto, sendo, em seguida, enviados para a Delegação mais próxima da residência dos requerentes, para a realização do exame pericial.

As investigações de paternidade fora de um processo judicial, principalmente quando realizadas por laboratórios privados, devem ter em consideração o Parecer da Comissão de Bioética da Sociedade Portuguesa de Genética Humana (SPGH), de 4 de Outubro de 2010, sobre "Normas de bioética e questões jurídicas na realização de testes de paternidade fora de um processo judicial em Portugal", até à implementação de um diploma legal, que enquadre este tipo de investigações no ordenamento jurídico português (Santos et al., 2010).

\subsection{INVESTIGAÇÃO DE PATERNIDADE}

Como referido anteriormente, o objetivo da investigação de paternidade é o de determinar se o pretenso pai em questão é ou não excluído da paternidade do investigante. Com esse fim, estudam-se os vários sistemas de marcadores genéticos (STRs), que conferem, nos casos mais comuns de investigação de paternidade, ao trio p.pai/mãe/filho(a), uma 
individualidade biológica determinada pelo perfil genético dos intervenientes no processo.

\subsubsection{Investigação de paternidade do trio p.pai/mãe/filho(a)}

Nas situações mais comuns de investigação de paternidade, as quais configuram mais de $80 \%$ das investigações de parentesco e que se baseiam no estudo dos três intervenientes, p.pai/ mãe/filho(a) sendo o par mãe/filho considerado um par biológico verdadeiro, determinam-se os alelos que devem ser, obrigatoriamente, transmitidos pelo pai biológico (Tabela I).

Tabela I - Perfis genéticos dos intervenientes numa investigação biológica de paternidade com estudo do trio p.pai/ mãe/filho(a).

\begin{tabular}{|l|l|l|l|}
\hline Locus & p.pai & mãe & filho \\
\hline D3S1358 & 16 & 15,18 & 15,16 \\
\hline TH01 & $9,9.3$ & 8,9 & 8,9 \\
\hline D21S11 & $29,31.2$ & 28,30 & 28,29 \\
\hline D18S51 & 12,14 & 14 & 12,14 \\
\hline PentaE & 10,11 & 11,16 & 10,16 \\
\hline D5S818 & 12 & 11,12 & 11,12 \\
\hline D13S317 & 11,13 & 12 & 11,12 \\
\hline D7S820 & 7,9 & 8,10 & 7,10 \\
\hline D16S539 & 13,14 & 11,12 & 12,14 \\
\hline CSF1PO & 11,12 & 11,12 & 11 \\
\hline PentaD & 11,12 & 11,14 & 11,14 \\
\hline vWA & 14,17 & 17,18 & 17 \\
\hline D8S1179 & 11,16 & 10 & 10,11 \\
\hline TPOX & 8,11 & 8,11 & 8,11 \\
\hline FIBRA & 20,24 & 21,23 & 20,23 \\
\hline D2S1338 & 17,18 & 18,23 & 17,18 \\
\hline D19S433 & 12,13 & 14,16 & 12,14 \\
\hline
\end{tabular}

Na Tabela I, exemplificam-se os perfis genéticos correspondentes a um caso de investigação de paternidade, sendo que o pretenso pai possui as características genéticas que deveriam ser transmitidas, pois possui os alelos que a mãe não transmite ao filho. Esta situação configura uma condição de não exclusão de paternidade.

Quando não existem incompatibilidades genéticas nos 17 sistemas estudados, como no caso presente, são efetuados cálculos estatísticos, de modo a determinar o índice de paternidade e a probabilidade de paternidade que o pretenso pai tem de ser o pai biológico do investigante. Este cálculo atribui ao pretenso pai um valor estatístico, tendo em consideração a genética populacional a que pertence o indivíduo em estudo.

Nos casos mais comuns, os cálculos estatísticos são efetuados considerando ausência de parentesco biológico - como pai, filho ou irmão, entre o pretenso pai indigitado e o pai biológico, uma vez que, a acontecer a existência de parentesco biológico, esta situação terá implicações nos resultados obtidos e, por conseguinte, deve ser tida em consideração aquando dos cálculos.

\subsubsection{Investigação de paternidade com dois pretensos pais}

Num processo com dois pretensos pais, esta investigação efetua-se sempre recorrendo ao estudo comparativo dos perfis genéticos dos trios em questão: p.pai1/mãe/filho(a) e p.pai2/ mãe/filho(a), ver Tabela II. Do mesmo modo, em todos os casos de investigação de paternidade com diversos pretensos pais, a base de estudo será, sempre que possível, o trio p.pai/ mãe/filho(a). 
Tabela II - Perfis genéticos dos intervenientes numa investigação biológica de paternidade com dois pretensos pais (p.pai1 e p.pai2).

\begin{tabular}{|l|c|c|c|c|c|}
\hline Locus & p.pai1 & mãe & filho & p.pai2 & Observação \\
\hline D3S1358 & 15,18 & 14,16 & 15,16 & 14,16 & Incomp. \\
\hline TH01 & 6,9 & 7,8 & 6,7 & 7,8 & Incomp. \\
\hline D21S11 & 29,30 & $28,32.2$ & 28,29 & $30,32.2$ & Incomp. \\
\hline D18S51 & 16 & 17,18 & 16,17 & 15,17 & Incomp. \\
\hline PentaE & 12,17 & 11,14 & 12,14 & 11,13 & Incomp. \\
\hline D5S818 & 11,13 & 9,13 & 11,13 & 11,12 & \\
\hline D13S317 & 11 & 12,13 & 11,12 & 11,12 & \\
\hline D7S820 & 11,12 & 10,11 & 10,11 & 8,10 & \\
\hline D16S539 & 9,10 & 10,11 & 9,10 & 10,11 & Incomp. \\
\hline CSF1PO & 10,11 & 10,12 & 11,12 & 7,11 & \\
\hline PentaD & 8,9 & 9,11 & 8,9 & 8,11 & \\
\hline vWA & 15,17 & 18,19 & 15,18 & 15,16 & \\
\hline D8S1179 & 15,16 & 12,16 & 12,16 & 12,15 & \\
\hline TPOX & 8 & 9,10 & 8,9 & 11 & Incomp. \\
\hline FIBRA & 23,25 & 23,24 & 23,24 & 18,27 & Incomp. \\
\hline D2S1338 & 17,25 & 19,21 & 19,25 & 19,23 & Incomp. \\
\hline D19S433 & $13,15.2$ & $14,14.2$ & $14,15.2$ & 14,15 & Incomp. \\
\hline
\end{tabular}

O pretenso pai 1 não apresenta qualquer incompatibilidade genética nos 17 loci STR estudados, configurando uma situação de não exclusão de paternidade. No caso de existirem incompatibilidades genéticas entre o pretenso pai e o investigante, o pretenso pai será excluído da paternidade em questão, quando se detetarem três ou mais incompatibilidades genéticas. No caso do pretenso pai 2, em que foram detetadas dez incompatibilidades genéticas nos 17 sistemas estudados, este indivíduo fica excluído da paternidade em investigação.

\subsection{CÁLCULOS ESTATÍSTICOS}

\section{EM INVESTIGAÇÃO DE PATERNIDADE}

Para a investigação biológica de paternidade, em casos compostos pelo trio p.pai/mãe/filho(a) deve ser determinado o índice de paternidade (IP), sendo para isso usada a análise de verosimilhança LR (do ing. likelihood ratio), entre a probabilidade do pretenso pai ser o pai biológico do(a) filho(a) (H0) e a probabilidade do pai biológico ser um indivíduo ao acaso da população (H1). Para cada uma das situações anteriores, parte-se de uma 
probabilidade a priori de 0,5 , uma vez que não dispomos de informação sobre qual das duas condições tem maior probabilidade de ser verdadeira (Gjertson et al., 2007).

$O$ índice de paternidade é calculado pela seguinte forma: $I P=X / Y=H O / H 1$, em que $X=H 0$, sendo $\mathrm{HO}$ a probabilidade do p.pai ser pai biológico do filho(a)) e $\mathrm{Y}=\mathrm{H} 1$, sendo $\mathrm{H} 1$ a probabilidade de um indivíduo ao acaso na população ser pai biológico do filho(a).

Assim, considera-se que $X$ é o produto das probabilidades que o pretenso pai tem de transmitir os alelos partilhados ao filho, e $\mathrm{Y}$ o produto das probabilidades de um indivíduo ao acaso da população, transmitir, ao filho em análise, os alelos paternos, sendo o valor de $Y$ dado pelo estudo populacional das frequências alélicas dos vários loci.

Outro parâmetro, normalmente calculado, é a probabilidade de paternidade $(W$, derivado da palavra alemã Wahrscheinlichkeit que significa probabilidade) que, apesar de não ser o mais correto do ponto de vista científico, pode fornecer uma mais fácil perceção para o destinatário final dos resultados, acerca da possibilidade do pretenso pai ser ou não o pai biológico do filho.

O índice de paternidade e a probabilidade de paternidade $\mathrm{W}=\mathrm{X} /(\mathrm{X}+\mathrm{Y})$ são valores facilmente interconvertíveis, do ponto de vista matemático. Como se compreenderá, os valores do índice de probabilidade ou da probabilidade de paternidade irão depender dos loci estudados e do grupo populacional em análise.

Considerando o exemplo do locus TH01, em que o pretenso pai transmite o alelo 9.3 ao filho:
p.pai1
mãe
filho(a)
$6,9.3$
$9.3,9.3$
9.3,9.3

Valor de $X=0,5$

Valor de $Y=$ frequência alelo 9.3 na população $=0,2642$

$\mathrm{IP}=\mathrm{X} / \mathrm{Y}=0,5 / 0,2642=1,8925$

$P=X /(X+Y)=0,6542(65,42 \%)$

No caso do estudo dos 17 sistemas, os valores de $\mathrm{X}$ e de $\mathrm{Y}$ correspondem ao produto dos valores obtidos para os diversos loci. Assim, com os 17 loci dos AmpFeSTR $®$ Identifiler ${ }^{\circledR}$ (/Direct/Plus) e PowerPlex® 16 (/HS) System, utilizados na maioria dos Laboratórios Forenses, os valores de IP obtidos são, normalmente, superiores a 1.000.000, o que corresponde a valores de $\mathrm{W}$ superiores a 99,9999\%, podendo ocorrer valores para IP da ordem de 10.000.000.000.000 e correspondentes W da ordem de 99,99999999999\%.

Podem considerar-se, normalmente, como limites mínimos, respetivamente, valores de IP $=1.000 .000$ e de $W=99,9999 \%$, para as investigações de paternidade efetuadas através do estudo do trio p.pai/mãe/filho(a), considerando os 17 loci STR e a população habitualmente em estudo no Laboratório.

\subsection{INCOMPATIBILIDADES GENÉTICAS}

Numa investigação de paternidade, obtendo-se diversas incompatibilidades genéticas (3, 4, 5 ou mais) entre p.pai/filho(a) num estudo com 17 loci STR, considera-se que o pretenso pai está excluído da paternidade em questão. 
Mas o que considerar num caso em que se deteta somente uma incompatibilidade entre o pretenso pai e um filho, num estudo com 17 STRs?

Em investigação biológica de paternidade, os STRs utilizados devem ter uma baixa taxa de mutação, como já referido em capítulos anteriores. Contudo, observam-se mutações em, praticamente, todos os loci STR de interesse forense, as quais devem ser equacionadas na resolução de algumas situações particulares.

Podem ser obtidos vários tipos de mutações, seja por inserção de uma unidade de repetição, por deleção de uma unidade de repetição ou por substituição pontual de uma base. As mutações por inserção ou deleção encontram-se localizadas na zona de repetição da estrutura dos STRs, enquanto que a mutação por substituição pontual é detetada, com maior frequência, quando ocorre na zona de ligação dos primers.

Uma mutação ao nível da região de repetição tem como consequência a observação de uma incompatibilidade mãe/filho ou p.pai/ filho, que se traduz numa alteração do número de repetições do alelo, sendo mais frequente a inserção ou deleção de uma unidade de repetição. Contudo, inserções ou deleções de 2 unidades de repetição têm, também, sido detetadas, em casos de não exclusão de paternidade.

Na Tabela III, verificam-se três exemplos de incompatibilidades genéticas obtidas num único locus (vWA, D16S539 ou FGA), detetadas aquando das respetivas investigações de paternidade, com o estudo dos 17 loci STR utilizados na rotina laboratorial.
Tabela III. Exemplos de incompatibilidades genéticas obtidas em três casos de investigação de paternidade.

\begin{tabular}{|c|c|c|c|c|}
\hline Caso \# & $\begin{array}{c}\text { Mutação } \\
\text { no locus }\end{array}$ & p.pai1 & mãe & filho \\
\hline $\mathbf{1}$ & vWA & 17,17 & 15,17 & 15,16 \\
\hline $\mathbf{2}$ & D16S539 & 11,13 & 9,13 & 9,12 \\
\hline $\mathbf{3}$ & FGA & 19,22 & 23,25 & 23,25 \\
\hline
\end{tabular}

Da análise destes três casos destacam-se os seguintes aspetos:

a) A incompatibilidade genética apresentada em vWA pode ser devida a uma mutação p.pai/filho, por deleção de uma unidade de repetição do locus, sendo que o alelo 17 passou a alelo 16 durante o processo de meiose. A mãe transmitiu o alelo 15 ao filho. Na Tabela IV, apresenta-se uma incompatibilidade genética por inserção de uma unidade de repetição em D7S820 (p.pai alelo8/filho alelo9).

b) No locus D16S539, sendo o pretenso pai 11,13 e o filho 9,12 , ocorreu uma das seguintes situações - inserção de uma unidade de repetição do alelo 11 resultando o alelo 12; ou uma deleção de uma unidade de repetição do alelo 13 passando a alelo 12, não sendo possível saber, ao certo, qual destas situações ocorreu na realidade. A mãe transmitiu o alelo 9 ao filho.

c) No caso do locus FGA, a mãe pode transmitir o alelo 23 ou o alelo 25, sendo mais provável que tenha transmitido o alelo 25 , existindo a possibilidade de inserção de uma unidade de repetição do alelo 22 para alelo 23 no caso paterno. 
Tabela IV. Investigação de paternidade com 17 loci STR e deteção de uma incompatibilidade genética em D7S820.

\begin{tabular}{|l|l|l|l|l|}
\hline Locus & p.pai1 & mãe & filho & Observação \\
\hline D3S1358 & 15,16 & 15,18 & 16,18 & \\
\hline TH01 & $6,9.3$ & $8,9.3$ & 9.3 & \\
\hline D21S11 & $28,33.2$ & $29,31.2$ & $28,31.2$ & \\
\hline D18S51 & 19,20 & 16,18 & 18,19 & \\
\hline PentaE & 10,12 & 12,13 & 12 & \\
\hline D5S818 & 12 & 10,11 & 10,12 & \\
\hline D13S317 & 11,13 & 11,12 & 11,13 & \\
\hline D7S820 & 8,10 & 11,12 & 9,11 & Incomp. \\
\hline D16S539 & 9,14 & 11,12 & 12,14 & \\
\hline CSF1PO & 12,13 & 10,11 & 10,12 & \\
\hline PentaD & 9,14 & 9,11 & 9,14 & \\
\hline vWA & 16,17 & 17,20 & 17,20 & \\
\hline D8S1179 & 12,14 & 10,11 & 10,14 & \\
\hline TPOX & 8,9 & 9,10 & 8,10 & \\
\hline FIBRA & 18,21 & 22,26 & 21,26 & \\
\hline D2S1338 & 23,24 & 17,19 & 19,23 & \\
\hline D19S433 & $14,14.2$ & 13,14 & 13,14 & \\
\hline
\end{tabular}

Em todas estas situações foram obtidos índices de paternidade superiores a 100.000.000, considerando os restantes 16 loci STR, nos quais não se detetaram incompatibilidades. Os cálculos estatísticos finais efetuados em investigações de paternidade com a deteção de uma incompatibilidade genética entre p.pai/filho, são realizados tendo em consideração a taxa de mutação do locus em que se deteta a incompatibilidade, sendo este valor determinado a priori através de estudos populacionais.

As taxas de mutação dos vários microssatélites estudados variam, sendo que a taxa de mutação paterna média é da ordem de 0,341\%, considerando o estudo das meioses maternas e paternas efetuado na população portuguesa. A taxa de mutação num determinado loci é dada pela razão entre o número de mutações obtidas nesse loci e o número de meioses estudadas. Por outro lado, detetou-se que a taxa de mutação paterna é 10 vezes superior à taxa de mutação materna.

Deve salientar-se a possibilidade de ocorrência simultânea de duas incompatibilidades genéticas em casos de não-exclusão, atendendo aos 17 loci STR estudados. No entanto, estas incompatibilidades devem ser compatíveis com valores de probabilidade de paternidade superiores a 99,99\% e índices de paternidade superiores a 10.000, quando equacionadas as respetivas taxas de mutação nos cálculos estatísticos.

Para além de inserções e deleções, podem, também, ocorrer substituições pontuais ao nível do ADN, localizando-se, mais frequentemente, na zona de ligação dos primers. Esta característica pode ter como consequência a não deteção de um determinado alelo, por alteração da sequência desta zona de ligação, de modo a não ser possível ligar o primer à sequência a amplificar.

Este facto é particularmente determinante no estudo do locus vWA com a utilização de primers de diferentes marcas comerciais.

Como se pode observar na Figura 1, a utilização de diferentes sistemas multiplex pode conduzir à deteção de diferentes genótipos. Esta situação, embora rara, deve ser tida em consideração na interpretação dos casos na prática forense. 
Figura 1. Diferentes genótipos de vWA obtidos com diferentes sistemas multiplex.

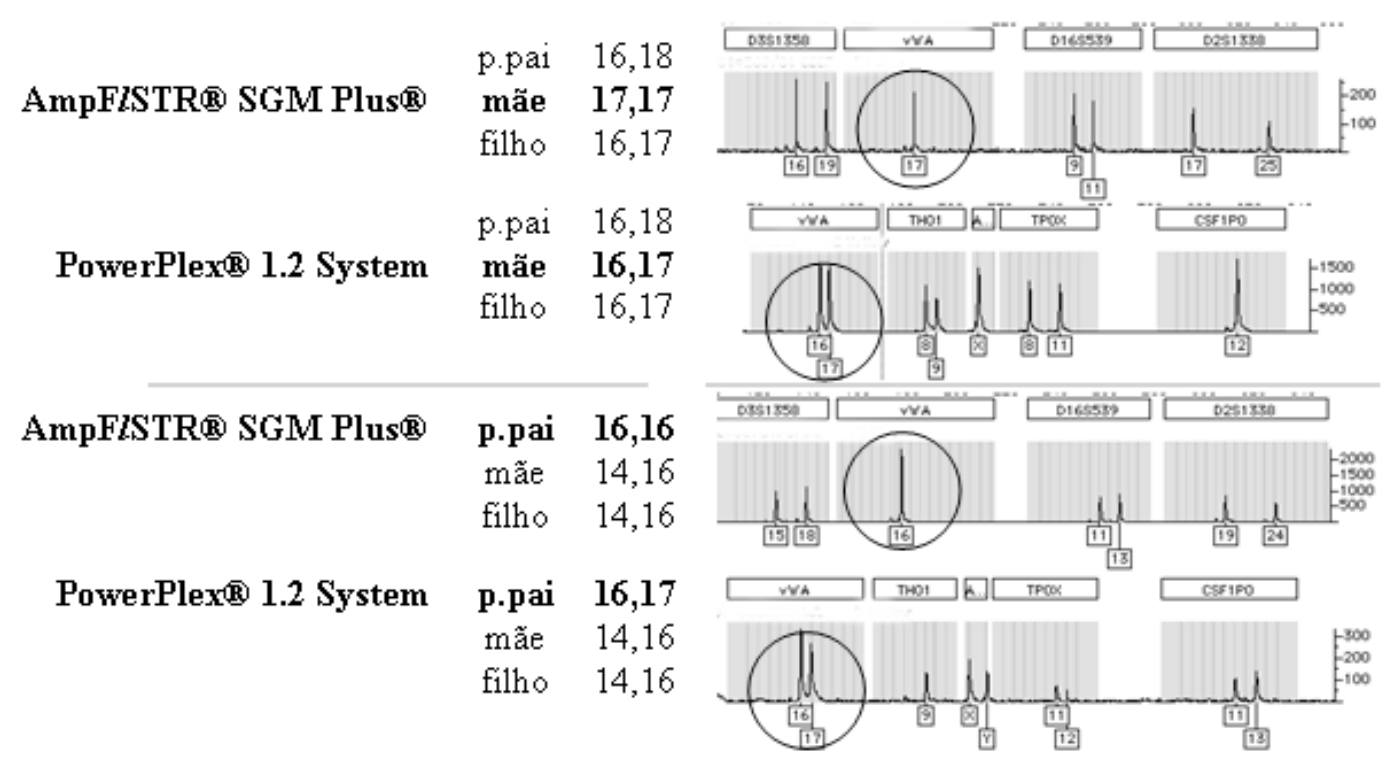

Para avaliar esta situação deve ser efetuado o estudo da sequência do locus na zona de ligação do primer, verificando-se uma substituição pontual da sequência normal desta zona, o que não permite a ligação do primer nas condições normais de amplificação, e, desse modo, não é amplificado um dos alelos, utilizando o multiplex SGM Plus $\circledR$, como exemplificado para as amostras indicadas na Figura 1.

O estudo da sequenciação dos loci de ADN e das mutações ao nível destes loci, necessário para uma pormenorizada interpretação das perícias, constitui uma das atribuições dos Laboratórios de Genética Forense. Na introdução de novas metodologias e de novos loci de ADN, estes estudos prefiguram um dos campos de maior interesse no entrecruzar da Genética Forense e da Genética Populacional.

\subsection{INVESTIGAÇÃO DE PATERNIDADE EM CASOS COM IRMÃOS}

Atualmente, em cerca de $2 \%$ dos casos de investigação de paternidade, é solicitado o estudo da paternidade de 2 ou mais irmãos. A generalidade destes casos é efetuada com base nos respetivos trios - p.pai/mãe/irmão1 e p.pai/ mãe2/irmã2, como se reflete na Figura 2.

Após a análise dos perfis genéticos, e considerando a mãe como mãe biológica, estes processos podem conduzir a três tipos de conclusões: 1) não exclusão do pretenso pai da paternidade dos dois irmãos; 2) exclusão da paternidade de um dos irmãos e não exclusão do outro; 3) exclusão do pretenso pai da paternidade dos dois irmãos. 
Figura 2. Investigação de paternidade em casos de estudo de 2 irmãos recorrendo ao estudo dos respetivos trios.

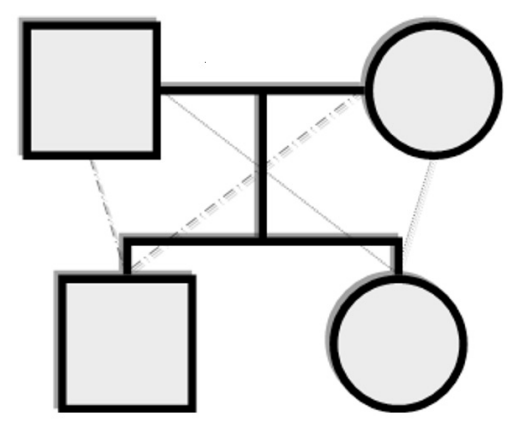

Como caso particular do estudo de irmãos, o estudo de gémeos representa cerca de 0,25\% da casuística total. No caso de gémeos dizigóticos (Dz), de sexo diferente, ou gémeos monozigóti$\cos (\mathrm{Mz})$, do mesmo sexo e normalmente com o mesmo perfil genético, a análise genética conduzirá a dois tipos de conclusões: 1) não exclusão da paternidade; 2) exclusão da paternidade dos gémeos, como indicado na Figura 3.

Mas nestes casos, pode também configurar-se uma terceira situação: não exclusão do pretenso pai da paternidade de um dos gémeos, mas exclusão da paternidade em relação ao outro gémeo. Estas situações especiais de gémeos dizigóticos, podem resultar de relações sexuais, durante um ciclo poliovulatório de superfecundação - se ocorrem com o mesmo indivíduo, os gémeos são homopaternos; se ocorrerem com indivíduos
Figura 3. Investigação de paternidade de gémeos - não exclusão versus exclusão.

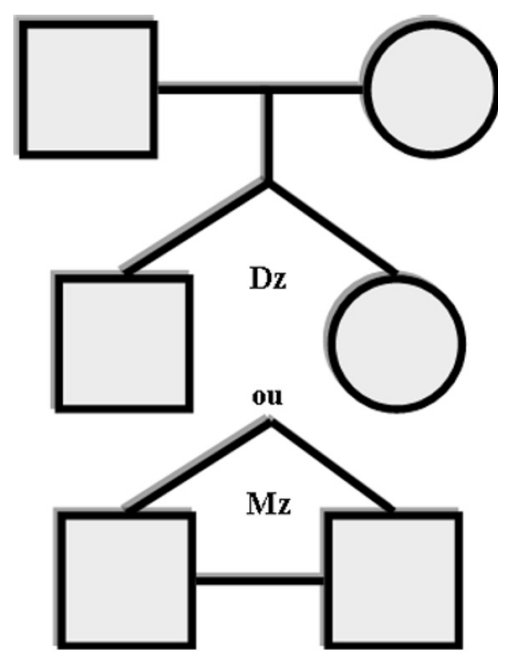

diferentes, os gémeos podem ser heteropaternos, isto é, têm pais biológicos diferentes, situações, que embora raras, são detetadas no decurso das investigações de paternidade.

O perfil genético de gémeos heteropaternos encontra-se exemplificado no estudo de três loci STR, sendo que o pretenso pai 1 se encontra excluído da paternidade em relação ao gémeo 2 e não excluído em relação ao gémeo 1, estando representados a negrito os alelos que o pai biológico deveria transmitir ao gémeo 2 (Tabela $V$ ).

Tabela V. Investigação de paternidade de gémeos heteropaternos, sendo que o pretenso pai 1 está excluído da paternidade do gémeo 2 e não excluído em relação ao gémeo 1 .

\begin{tabular}{|c|c|c|c|c|}
\hline Locus & p.pai1 & gémeo1 & gémeo2 & mãe \\
\hline TH01 & 6,7 & 6,7 & $6,9.3$ & 6,7 \\
\hline vWA & 15,17 & 15,16 & 16,16 & 16,16 \\
\hline SE33 & $22,31.2$ & $17,31.2$ & 17,19 & $13.2,17$ \\
\hline
\end{tabular}


Do mesmo modo, em relação ao pretenso pai 2 (Tabela VI), verifica-se que este se encontra excluído da paternidade do gémeo 1 e não excluído em relação ao gémeo 2, embora apresente, no locus SE33, uma mutação por deleção de 1 unidade de repetição (alelo 20 / alelo 19).

Tabela VI. Investigação de paternidade de gémeos heteropaternos, sendo que o pretenso pai 2 está excluído da paternidade do gémeo 1 e não excluído em relação ao gémeo 2 .

\begin{tabular}{|l|c|c|c|c|}
\hline Locus & p.pai2 & gémeo1 & gémeo2 & mãe \\
\hline TH01 & $9,9.3$ & 6,7 & $6,9.3$ & 6,7 \\
\hline vWA & 16,17 & 15,16 & 16,16 & 16,16 \\
\hline SE33 & $20,23.2$ & $17,31.2$ & 17,19 & $13.2,17$ \\
\hline
\end{tabular}

Este estudo foi efetuado em colaboração com o Instituto de Medicina Legal de Munster, que veio a confirmar a mutação do alelo 20 para alelo 19, através da sequenciação do locus SE33, detetando-se, também, um maior número de exclusões com o estudo de outros loci STR - 10 exclusões no par p.pai1/gémeo2 e 8 exclusões no par p.pai2/gémeo1 (Geada et al., 2001). A probabilidade de paternidade foi superior a 99,99999\% (IP> 10.000.000) para cada par de não exclusão, o que confirma a hipótese de gémeos heteropaternos - p.pai1/gémeo1 e p.pai2/gémeo2.

\subsection{INVESTIGAÇÃO DE PATERNIDADE EM CASOS COM AUSÊNCIA DE MÃE}

Na rotina forense, são, também, solicitados processos de investigação de paternidade em casos com ausência de mãe, quer por esta se encontrar em parte incerta, quer por ter falecido. Nestes processos, que, atualmente, configuram
$6 \%$ do total das investigações de paternidade, efetua-se, de igual modo, o perfil genético dos intervenientes com 17 loci STR.

Na Tabela VII, exemplifica-se um caso de investigação de paternidade na ausência de mãe, estando, representados a negrito, os alelos que podem ser partilhados entre o pretenso pai e o filho, verificando-se, pelo menos, a partilha de um alelo, podendo, no entanto, ser partilhados os dois alelos, como nos loci D7S820, vWA e D19S433.

Tabela VII. Investigação de paternidade na ausência de mãe.

\begin{tabular}{|l|c|c|c|}
\hline Locus & p.pai & mãe & filho \\
\hline D3S1358 & 15,17 & & 16,17 \\
\hline TH01 & $\mathbf{1 9}$ & & 15,19 \\
\hline D21S11 & $\mathbf{1 1}$ & & 8,11 \\
\hline D18S51 & $\mathbf{1 7 , 2 6}$ & & 17,20 \\
\hline PentaE & $\mathbf{1 2}$ & & 12,13 \\
\hline D5S818 & $\mathbf{2 9 , 3 0 . 2}$ & & 29 \\
\hline D13S317 & 11,12 & & 12,18 \\
\hline D7S820 & $\mathbf{1 5}$ & & 15 \\
\hline D16S539 & $\mathbf{6 , 7}$ & & 6,9 \\
\hline CSF1PO & $\mathbf{2 1 , 2 4}$ & & 21 \\
\hline PentaD & $\mathbf{1 1 , 1 3}$ & & 11,14 \\
\hline vWA & $\mathbf{1 1 , 1 3}$ & & 11,13 \\
\hline D8S1179 & $\mathbf{1 0 , 1 1}$ & & 10,12 \\
\hline TPOX & $\mathbf{8 , 9}$ & & 9,11 \\
\hline FIBRA & $\mathbf{1 2 , 1 3}$ & & 10,12 \\
\hline D2S1338 & $\mathbf{1 5}$ & & 10,15 \\
\hline D19S433 & $\mathbf{1 1 , 1 2}$ & & 11,12 \\
\hline
\end{tabular}

Por vezes, é necessário aumentar o número de loci a incluir neste tipo de perícias, pois estes casos, considerados como incompletos por ausência de um dos intervenientes, podem necessitar de um estudo mais aprofundado, devido aos 
problemas de incompatibilidades genéticas que possam surgir.

De salientar que este tipo de perícias de investigação de paternidade, só deve ser realizado, na ausência de mãe, em situações lineares de parentesco, isto é, situações em que não esteja subjacente qualquer hipótese de implicação de outro familiar materno ou paterno, respetivamente, como mãe ou como pretenso pai, o que pode ocorrer, por exemplo, nos casos de imigração.

Nestes casos será necessário um estudo familiar mais alargado, se possível, ou o estudo de um maior número de marcadores STRs, assim como a inclusão de outro tipo de marcadores genéticos, como Y-STRs, X-STRs, ADN mitocondrial ou SNPs autossómicos, consoante o caso em investigação.

Relativamente ao cálculo estatístico do índice de paternidade ou da probabilidade de paternidade, estes podem ser calculados através de fórmulas matemáticas específicas para estes casos, ou efetuados através de um programa informático específico, como adiante será referido.

\subsection{INVESTIGAÇÃO DE MATERNIDADE}

Na casuística de qualquer Laboratório de Genética Forense, são solicitados casos de investigação de maternidade, que, no essencial, são estudados do mesmo modo que os casos de investigação de paternidade na ausência de mãe, e que são abordados, em pormenor, no capítulo de Identificação Biológica.

Resumidamente, serão determinados os perfis genéticos dos indivíduos em questão, em relação aos 17 loci STR, e verificada a existência ou não de incompatibilidades genéticas nos diversos loci. Nestes casos, podem também ser estudados outros marcadores genéticos, essencialmente, ADN mitocondrial e X-STRs.

Relativamente ao cálculo estatístico do índice de maternidade ou da probabilidade de maternidade pode, também, ser efetuado através de fórmulas matemáticas específicas, ou através de software informático específico.

\subsection{INVESTIGAÇÃO DE PATERNIDADE NA AUSÊNCIA DO PRETENSO PAI}

A investigação de paternidade na ausência do pretenso pai, que configura cerca de $5 \%$ do total das investigações de paternidade, é efetuada através do estudo dos familiares do pretenso pai (Figura 4), recorrendo, frequentemente, ao estudo dos pretensos avós paternos, de outros filhos do pretenso pai ou de irmãos do pretenso pai. O cálculo estatístico será efetuado recorrendo a software específico, a analisar posteriormente.

Figura 4. Investigação de paternidade na ausência do pretenso pai, representado por $\mathbf{X}$, e recorrendo ao estudo de familiares paternos.

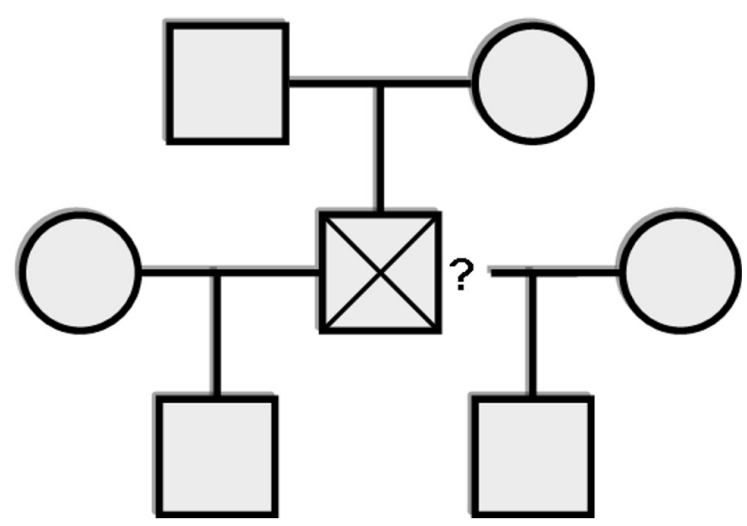


Figura 5 - Investigação de paternidade de pretensos irmãos consanguíneos, na ausência do pretenso pai biológico.

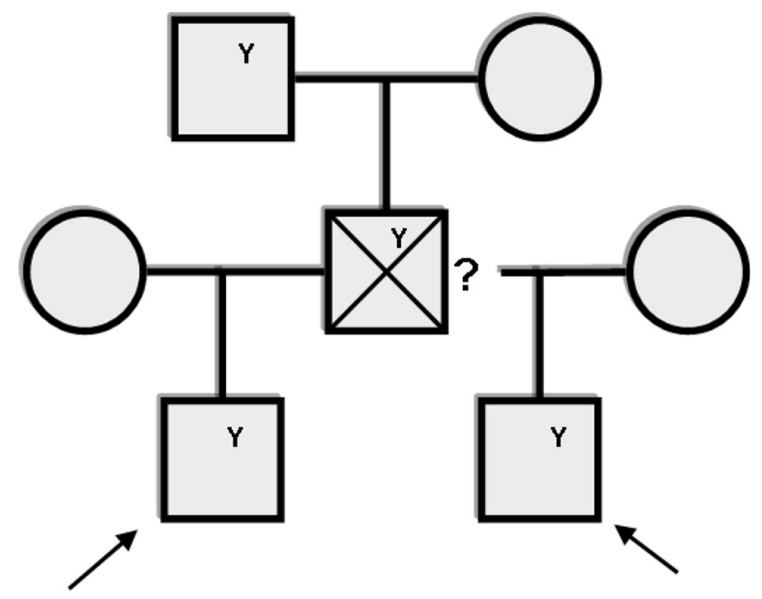

\subsubsection{Estudo de pretensos irmãos consanguíneos}

Uma das situações frequentemente solicitadas à Genética Forense, na ausência do pretenso pai, prende-se com a hipótese de dois indivíduos poderem ser irmãos consanguíneos, isto é, filhos do mesmo pai, mas de diferentes mães (Figura 5).

Em casos de filhos de sexo masculino, para além do estudo de STRs autossómicos, pode ser efetuado o estudo de Y-STRs, de modo a determinar se aqueles pertencem ou não à mesma linha paterna. No entanto, somente através dos STRs autossómicos é possível, na realidade, saber se os dois indivíduos, em estudo, são ou não irmãos consanguíneos.

De salientar que estes estudos podem, também, ser efetuados na ausência das respetivas mães, embora a determinação dos alelos que devem ser transmitidos pelo pai biológico sejam
Figura 6. Investigação de paternidade de pretensos irmãos consanguíneos, na ausência do pretenso pai biológico, recorrendo ao estudo de pretensos familiares paternos.

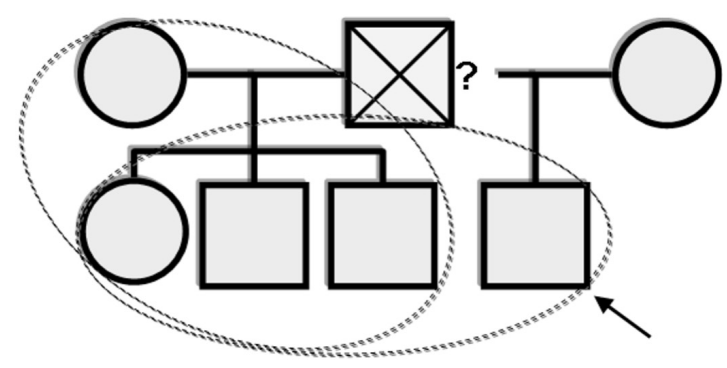

definidos, com maior precisão, com o estudo concomitante dos perfis genéticos mãe/filho, e posterior comparação dos alelos não partilhados.

Na Figura 6, encontra-se exemplificado outro caso de investigação de paternidade de pretensos irmãos consanguíneos, estando implicados outros familiares paternos, na ausência do pretenso pai, de modo a ser possível determinar se o pretenso pai ausente, pode ou não ser o pai biológico do filho assinalado na figura.

Este estudo pode ser realizado pela determinação dos perfis genéticos de todos os implicados para comparação, como os três filhos biológicos do indivíduo ausente e a mãe destes, ou no caso de não ser possível ter acesso a todos os familiares, pode, por exemplo, ser realizado somente com os pretensos irmãos, ou com um dos pretensos irmãos e a respetiva mãe.

Compreende-se, contudo, que quanto maior o número de familiares diretos para estudo genético, 
Figura 7. Estudo de pretensos irmãos, sem hipótese de comparação com outros familiares.

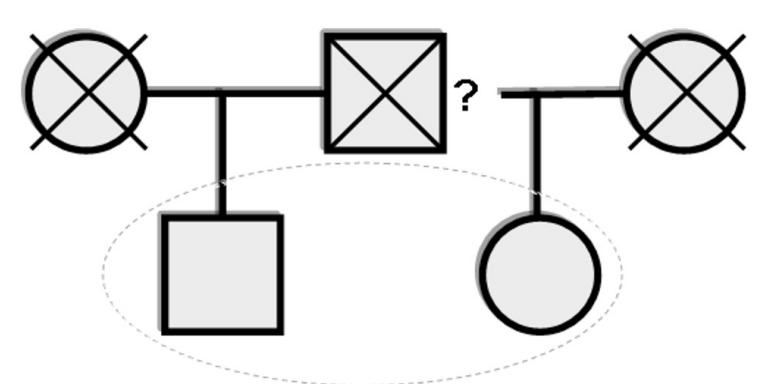

maior será a probabilidade de paternidade que pode ser obtida em casos incompletos, isto é, nos quais não é possível ter os perfis genéticos dos respetivos trios p.pai/mãe/filho(a) para estudo.

Mas uma investigação relativa a dois pretensos irmãos pode também ser efetuada recorrendo, somente, aos dois indivíduos para comparação (Figura 7). Diversos casos, nestas condições, são solicitados aos Laboratórios, como, por exemplo, o estudo de dois pretensos meios-irmãos adultos, sem hipótese de recurso a outros familiares, já falecidos, com o objetivo de averiguar a possibilidade de terem o mesmo pai, como meio de prova a apresentar em ação judicial de reconhecimento de paternidade.

\subsubsection{Estudo de pretensos irmãos germanos}

Mas os casos mais solicitados aos Laboratórios de Genética Forense, na ausência do pretenso pai, prendem-se com as situações como a exemplificada
Figura 8. Investigação de paternidade somente de um dos filhos, na ausência do pretenso pai.

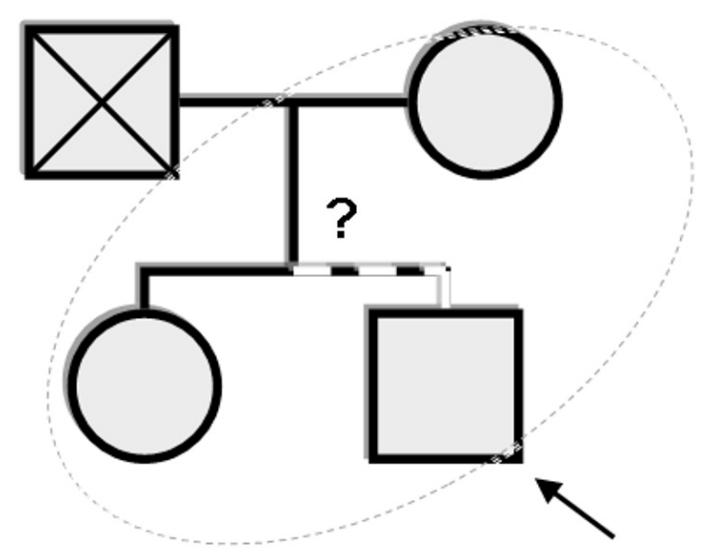

na Figura 8, em que se pretende averiguar a paternidade somente de um dos filhos, sendo que o pretenso pai se encontra ausente.

Encontrando-se estabelecida a maternidade dos dois filhos e a paternidade de um deles (neste caso da filha), pretende-se averiguar se o filho, em questão, pode ou não ter o mesmo pai biológico. Estes casos podem apresentar, consoante o perfil genético dos intervenientes, probabilidades da ordem de 99,999995\% dos dois indivíduos terem o mesmo pai biológico, podendo ser considerados como irmãos germanos (verdadeiros).

Podem, também, ser solicitadas investigações relativas a problemas do foro da imigração, como, por exemplo, no pedido efetuado em relação a dois indivíduos de etnia africana, da hipótese de estes poderem ou não ser irmãos germanos. Efetuado o estudo dos respetivos perfis genéticos, e através do software específico para o estudo de relações de parentesco, foram 
Figura 9. Investigação de paternidade na ausência do pretenso pai biológico e com possibilidade de estudo dos pretensos avós paternos.

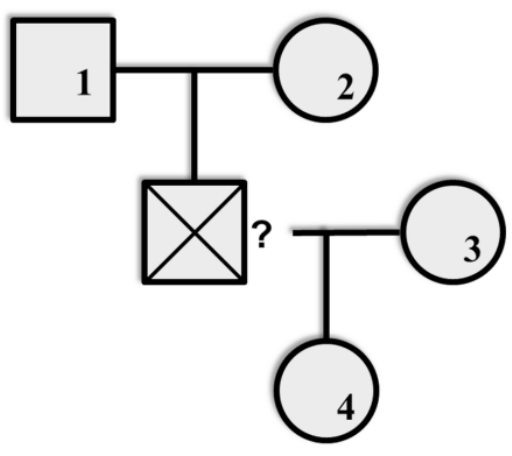

introduzidas as hipóteses de irmandade / ausência de relação de parentesco, verificando-se, para este caso, uma probabilidade de paternidade superior a 99,9\% de os dois indivíduos serem irmãos verdadeiros.

\subsubsection{Estudo de pretensos avós paternos}

Um dos tipos de processos mais solicitados no caso da ausência do pretenso pai, refere-se ao estudo de pretensos avós paternos e/ou de pretensos tios paternos, que configuram cerca de 70\% das investigações de paternidade na ausência de pretenso pai.

Nos casos de estudo dos pretensos avós paternos, será estudada a probabilidade de um filho dos pretensos avós paternos poder ser o pai biológico do indivíduo em investigação. Verifica-se na Figura 9, que os alelos não partilhados com a mãe, são detetados nos perfis genéticos do pretenso avô paterno e/ou da pretensa avó paterna.

\begin{tabular}{lcccc}
\hline \multicolumn{1}{c}{ Locus } & \multicolumn{1}{c}{ l. p.avô pat. 2. p.avó pat. } & 3. mãe & 4. filha \\
\hline D3S1358 & $\mathbf{1 5}$ & 14,18 & 16,18 & $\mathbf{1 5 , 1 6}$ \\
TH01 & 7,8 & 8,9 & 7 & 7 \\
D21S11 & $\mathbf{2 9 , 3 2 . 2}$ & $30,31.2$ & 30 & $\mathbf{2 9 , 3 0}$ \\
D18S51 & 12,14 & $\mathbf{1 3 , 1 4}$ & 12,16 & $\mathbf{1 3 , 1 6}$ \\
PentaE & 7,12 & 12,17 & 12,16 & $16, \mathbf{1 7}$ \\
D5S818 & $11, \mathbf{1 3}$ & $11, \mathbf{1 2}$ & 12,13 & $\mathbf{1 2 , 1 3}$ \\
D13S317 & 12 & 11,13 & 10,11 & $10, \mathbf{1 3}$ \\
D7S820 & $\mathbf{1 0}$ & $\mathbf{1 0 , 1 1}$ & 10,11 & $\mathbf{1 0 , 1 1}$ \\
D16S539 & $\mathbf{1 1}$ & 12 & 8,12 & $\mathbf{1 1 , 1 2}$ \\
CSF1PO & 10,12 & $10, \mathbf{1 4}$ & 10 & $10, \mathbf{1 4}$ \\
PentaD & $10, \mathbf{1 5}$ & 12,14 & 10,11 & $11, \mathbf{1 5}$ \\
vWA & $17, \mathbf{2 0}$ & 17 & 15 & $15, \mathbf{2 0}$ \\
D8S1179 & $\mathbf{1 3}$ & $\mathbf{1 3}$ & 11,12 & $12, \mathbf{1 3}$ \\
TPOX & $\mathbf{8}$ & 9,10 & 9,12 & $\mathbf{8 , 1 2}$ \\
FIBRA & 22,23 & 20,21 & 19,21 & $\mathbf{1 9 , 2 1}$ \\
D2S1338 & 17,23 & $\mathbf{2 3 , 2 4}$ & 16,2 & $20, \mathbf{2 3}$ \\
D19S433 & 15 & $\mathbf{1 2 , 1 3}$ & 14.2 & $\mathbf{1 2 , 1 4 . 2}$ \\
\hline
\end{tabular}

De salientar que em vários loci, podem ser detetados os dois alelos nos pretensos avós: por exemplo, no locus D5S818, a mãe pode passar à filha o alelo 12 ou o alelo 13, sendo que ambos estes alelos se encontram presentes nos perfis dos pretensos avós. O mesmo acontece com o locus D7S820. Ao nível do Fibra (FGA), em que o par mãe/filha apresenta o perfil 19,21, não se sabendo qual destes alelos será transmitido pela mãe, verifica-se que a pretensa avó paterna apresenta o alelo 21, não havendo, portanto qualquer tipo de incompatibilidade neste estudo. Efetuado o cálculo estatístico correspondente, obteve-se, em relação à filha, uma probabilidade de paternidade de 99,82\%, considerando, como pretenso pai, um indivíduo filho dos pretensos avós.

Os perfis genéticos são efetuados, normalmente através do estudo de STRs autossómicos, podendo ser complementados com STRs do cromossoma Y, no caso do indivíduo em estudo ser 
Figura 10. Investigação de paternidade, na ausência do pretenso pai biológico, mas com possibilidade de estudo do pretenso avô paterno e de uma irmã do pretenso pai.

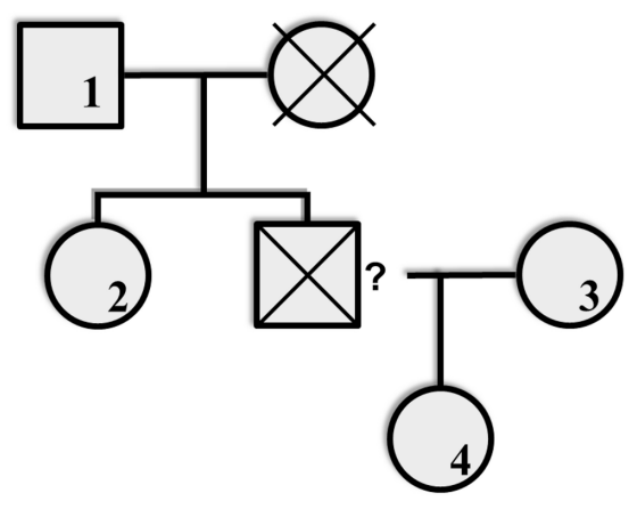

do sexo masculino, ou STRs do cromossoma $X$, no caso de ser do sexo feminino.

Do mesmo modo, outras investigações com pretensos familiares paternos, e na ausência do pretenso pai, podem ser efetuadas, como exemplificado na Figura 10, com recurso ao estudo do pretenso avô paterno e à irmã do pretenso pai. Considerando o par mãe/filha como um par verdadeiro, todos os alelos não partilhados com a mãe, são provenientes do pai biológico.

Na maioria dos loci, os alelos não partilhados são detetados no pretenso avô ou na irmã do pretenso pai, alelos que neste caso foram transmitidos pela pretensa avó paterna. Em loci, como D21S11 e D5S818, não se observaram nenhum dos alelos que, necessariamente, são transmitidos pelo pai biológico — alelo 30.2 no locus D21S11 e alelos 11,12 no locus D5S818, sendo que estes alelos devem ter sido transmitidos pela pretensa avó.

Apesar de não serem observados todos os alelos da filha, esta situação não configura, por

\begin{tabular}{|c|c|c|c|c|}
\hline Locus & 1. p.avô pat. & 2. irmã p.pai & 3. mãe & 4. filha \\
\hline D3S1358 & 17 & 17,18 & 16,17 & 16,17 \\
\hline Тн01 & $9,9.3$ & $7,9.3$ & 6,8 & 7,8 \\
\hline D21S11 & 29,31 & 31 & $29,33.2$ & $30.2,33.2$ \\
\hline D18S51 & 17,20 & 15,17 & $12,14.2$ & 12,15 \\
\hline PentaE & 5,13 & 5,12 & 9,10 & 5,10 \\
\hline D5S818 & 10,13 & 13,14 & 11,12 & 11,12 \\
\hline D13S317 & 12 & 11,12 & 11 & 11,12 \\
\hline D7S820 & 10,12 & 12 & 8,11 & 8,12 \\
\hline D16S539 & 9,13 & 9,12 & 9,12 & 9,12 \\
\hline CSFIPO & 8,12 & 10,12 & 12,13 & 12,13 \\
\hline PentaD & 7 & 7,11 & 13,14 & 11,13 \\
\hline vWA & 16,17 & 14,17 & 16 & 16,17 \\
\hline D8S1179 & 12,15 & 10,15 & 14,15 & 14,15 \\
\hline TPOX & 8,10 & 6,10 & 9,10 & 8,9 \\
\hline FIBRA & 24 & 20,24 & 19,23 & 19,24 \\
\hline D2S1338 & 19,22 & 19,24 & 15,18 & 18,24 \\
\hline D19S433 & $13,15.2$ & 13,14 & $12,15.2$ & 12,13 \\
\hline
\end{tabular}

si, uma situação de incompatibilidade genética, pois este tipo de investigação não é efetuado num trio, mas sim num caso incompleto de parentesco.

O cálculo estatístico da probabilidade de paternidade, em relação à menor, de um indivíduo filho de 1 (pretenso avô) e irmão de 2 (pretensa tia paterna) é de 99,75\%, cálculo efetuado através de um programa estatístico de estabelecimento de parentesco.

\section{FAMÍLIAS - SOFTWARE ESTATÍSTICO PARA RELAÇÕES DE PARENTESCO}

Diversos programas informáticos são utilizados nos Laboratórios Forenses, quer para o estudo estatístico das relações de parentesco, quer para os cálculos estatísticos nos casos de identificação. De entre estes programas, o programa Familias, desenvolvido por Petter Mostad e Thore Egeland 
Figura 11. Árvore genética para estudo da relação de parentesco.

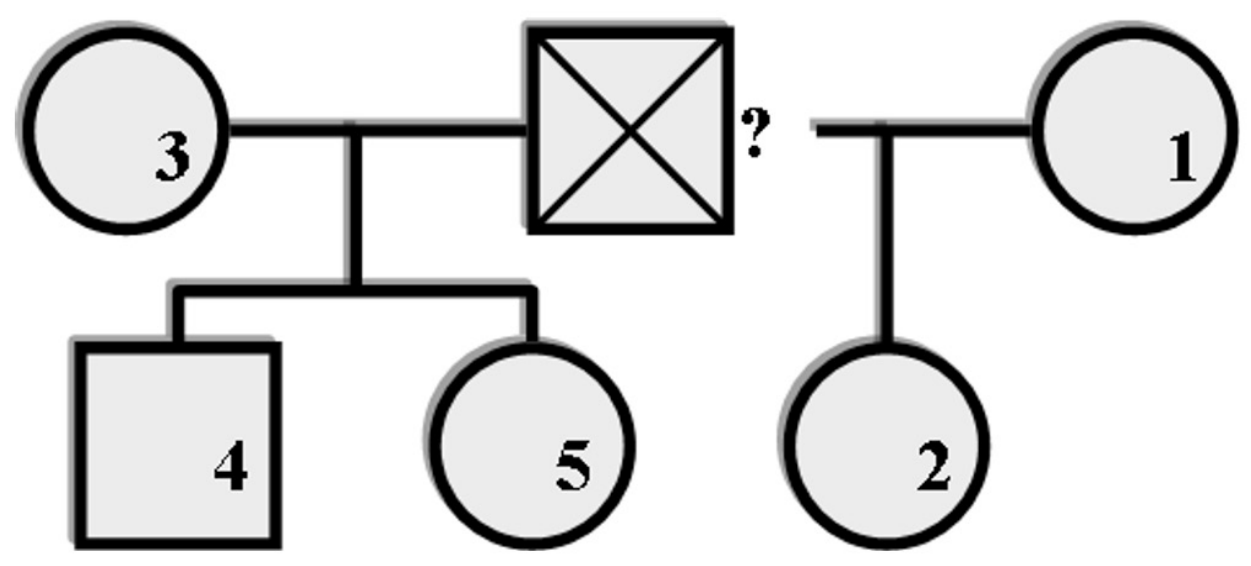

do Centro Computacional Norueguês, em cooperação com Bjørnar Olaisen, Margurethe Stenersen e Bente Mevåg do Instituto de Medicina Forense de Oslo, tem sido um dos mais utilizados, ao nível dos Laboratórios Forenses, para a determinação dos cálculos de paternidade em casos incompletos e/ou complexos, nos quais se podem incluir os casos com incompatibilidades genéticas (Egeland et al., 2000).

Este software é usado, por exemplo, para o cálculo das probabilidades no caso de se conhecer o perfil genético dos intervenientes, pretendendo-se, porém, determinar a sua relação familiar. Dado um grupo de indivíduos para estudo, o cálculo estatístico é efetuado tendo por base as diversas árvores familiares (pedigrees), que podem ser estabelecidas, sendo conhecidos alguns dos perfis genéticos individuais. Para estes cálculos é fundamental o conhecimento da genética populacional, relativamente às frequências dos alelos dos diversos loci estudados. Deste modo, o programa
Familias indicará qual o pedigree mais provável, e qual a sua probabilidade de ocorrência, em comparação com os outros pedigrees.

O caso mais simples de estudo será, efetivamente, o estudo de um trio p.pai/mãe/filho(a), de modo a determinar se o indivíduo é ou não o pai biológico do filho/a. O programa irá calcular a hipótese do pretenso pai ser na realidade o pai biológico, através do estudo dos perfis genéticos e introdução destes no programa informático. Nestes casos, haverá duas hipóteses alternativas, isto é, dois pedigrees alternativos - o indivíduo é o pai biológico versus o indivíduo não é o pai biológico.

Mas este programa torna-se mais aliciante, nas investigações complexas de parentesco, pois, nestes casos, os cálculos manuais seriam bastante complicados. Um exemplo destas situações é apresentado na Figura 11, em que o pretenso pai faleceu, e pretende-se determinar se a filha (2) é ou não irmã consanguínea (meia-irmã) dos filhos do pretenso pai, e portanto filha do pretenso pai falecido. 
Após o estudo do perfil genético de STRs autossómicos dos indivíduos implicados, introduzem-se os respetivos perfis no programa Familias, assim como a indicação das relações familiares estabelecidas e conhecidas: Carlota (1) é mãe da Maria (2); a Ana (3) é mãe do André (4) e da Luísa (5). Por outro lado, o André e a Luísa têm o mesmo pai biológico, o qual foi designado por Extramale 1, mas do qual não se conhece o perfil genético. O programa estabelecerá todos os pedigrees possíveis com os intervenientes para estudo, e indicará o valor da probabilidade obtido para cada pedigree, sendo então excluídos os pedigrees que não se relacionem com a hipótese de estudo em questão.

Assim, dos diferentes pedigrees desenhados pelo programa, pretende-se saber a hipótese de um indivíduo do sexo masculino, pai do André e da Luísa, ambos filhos da Ana, ser, também, o pai biológico da Maria, filha da Carlota (Tabela VIII).

\section{Tabela VIII. Pedigree da relação familiar que se pretende} estudar.

Pedigree: Ped32

Probability: 0,999275622022711

| Parent: | Child: |
| Carlota (1) | Maria (2)

| ExtraMale1 | Maria (2)

| Ana (3) | Luísa (5)

| ExtraMale1 | Luísa (5)

| Ana (3) | Andre (4)

| ExtraMale1 | Andre (4)

Um dos pedigrees dados pelo programa (Ped32) é, na realidade, a relação familiar que se pretende estabelecer, tendo-se obtido um valor de probabilidade de 99,927\%, para a hipótese de o pai do André e da Luísa ser, também, o pai da Maria, filha da Carlota, dada a base de dados populacional das frequências dos respetivos alelos STRs estudados neste caso.

Os casos complexos de investigação de parentesco serão analisados com base no programa Familias, sendo que as investigações de paternidade simples, com base no estudo do trio p.pai/ mãe/filho(a), podem, também, ser analisadas do mesmo modo, pois a base de dados de frequências alélicas de STRs será a mesma para os diversos tipos de investigação.

\section{CASOS COMPLEXOS DE ESTABELECIMENTO DE PARENTESCO}

As investigações de parentesco podem, por vezes, ter implicações sociais que extravasam o âmbito de um simples estabelecimento de parentesco. Algumas das solicitações efetuadas aos Laboratórios de Genética Forense prendem-se, por exemplo, com casos de imigração, que se podem tornar casos bastante complexos do ponto de vista social.

Mas outras situações existem, das quais os próprios meios de comunicação são eco, pela situação intrínseca aos mesmos. De entre os diversos exemplos que se podiam apontar, são apresentados dois casos: a) estabelecimento de parentesco entre recém-nascidos, com ausência de pai e mãe; b) hipótese de incesto, fenómeno que atualmente se tem verificado ser frequente, em vários países, e que tem uma repercussão social, não só sobre todos 
Figura 12. Árvore genética para estabelecimento de maternidade (a); árvore genética após o estudo do perfil genético dos intervenientes (b).

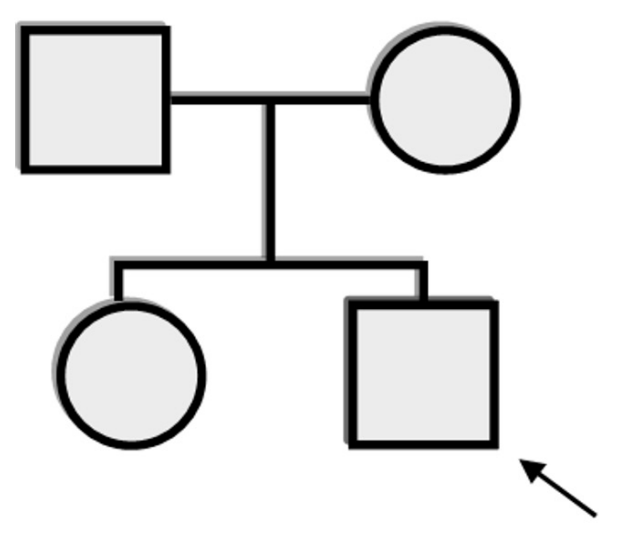

$\mathbf{a}$ os indivíduos implicados, como também na comunidade alvo.

No primeiro caso, dado o perfil genético de dois recém-nascidos, pode determinar-se, através do programa Familias, se estes têm algum tipo de relação de parentesco, tal como irmãos consanguíneos ou uterinos (meios irmãos), irmãos germanos (verdadeiros) ou se não têm nenhuma relação de parentesco.

Por outro lado, os casos de incesto solicitados para estudo podem ter diversas índoles. Num dos primeiros casos estudados pelo Laboratório, o Tribunal solicitava a investigação da hipótese de um menor ter sido concebido por uma relação de incesto pai/filha, sendo que o pai se encontrava ausente e o estudo só seria possível com base no perfil genético da avó, do tio do menor, da mãe e do menor. Com base nestes dados, foi possível reconstruir o perfil genético do pai da mãe, isto é, avô do menor, e estudar o trio em questão avô da menor (p.pai)/mãe/filho, tendo-se obtido uma probabilidade muito elevada do menor ter sido concebido através de uma relação de incesto pai/filha.

Outro tipo de investigação realizada, solicitava a confirmação da maternidade de um adolescente, sendo que os indivíduos enviados para estudo, referiam uma árvore genética como a apresentada na Figura 12.a.

Após os estudos genéticos efetuados, verificou-se a impossibilidade da árvore genética dada ser a verdadeira, pois o adolescente tinha como mãe a "própria irmã" (Figura 12.b). Este é mais um dos exemplos de casos de relações de incesto que vão sendo detetados e que fazem parte do tecido da nossa Sociedade, provocando danos psicológicos irreversíveis, em qualquer estrutura familiar e na comunidade envolvente. 


\section{COLHEITA E ENVIO}

\section{DAS AMOSTRAS PARA ESTUDO}

Relativamente à realização de perícias no INML, e de acordo com a legislação (Portaria n. ${ }^{\circ}$ 522/2007, de 30 de Abril), os Serviços de Genética devem assegurar, entre outros, a realização de perícias e exames de investigação biológica de parentesco, no âmbito das atividades da delegação e dos Gabinetes Médico-Legais que se encontrem na sua dependência, a solicitação das autoridades e entidades para o efeito competentes e do Presidente do Conselho Diretivo.

Assim sendo, os Serviços de Genética recebem solicitações para a realização de perícias de investigação biológica de parentesco dos diversos serviços das delegações do INML (e.g. Patologia Forense, para identificação de desconhecidos), dos Gabinetes Médico-Legais e das Forças de Segurança, incluindo a Polícia Judiciária (neste último caso, por exemplo, para averiguar a paternidade de menor cuja conceção possa ter sido fruto do crime de violação). O Ministério dos Negócios Estrangeiros pode, também, solicitar perícias de parentesco, em casos de pedidos de vistos para reunião familiar, mas, a maioria das perícias de investigação biológica de parentesco é solicitada pelos Tribunais, incluindo, principalmente, as averiguações oficiosas de paternidade.

Tal como nos restantes exames genéticos, a recolha, o acondicionamento e a preservação das amostras são fatores cruciais para a realização das perícias de investigação biológica de parentesco, pois se aquelas não forem corretamente executadas, o exame poderá ficar comprometido. Poderão mesmo não ser obtidos os perfis genéticos necessários para o estudo, mesmo que todo o trabalho seja realizado pelos melhores especialistas e usando as técnicas mais avançadas.

Como em qualquer outra perícia de investigação genética, a importância de uma adequada recolha e preservação de amostras na investigação biológica de parentesco não deve ser subestimada. Quer por questões de estandardização das amostras, quer para tornar as perícias mais rápidas e o menos invasivas possível para os envolvidos, as amostras de referências utilizadas consistem, principalmente, em amostras de saliva, mais propriamente de células do epitélio da mucosa bucal, recolhidas com zaragatoa bucal e, sempre que possível, em amostras de sangue obtidas por punção digital.

O primeiro passo para a recolha de amostras consiste em identificar o(s) indivíduo(s) presente(s) a exame e obter o seu consentimento, por escrito, para a realização da perícia. Assim, é realizado um auto de identificação e colheita de amostras biológicas, o qual deverá ser dado a ler ao(s) interveniente(s) e após o seu consentimento, o mesmo deverá assinar em como autoriza a realização da recolha das amostras e a realização do respetivo exame.

Durante a recolha deve ser tido algum cuidado, quer para evitar a contaminação das amostras, quer para garantir a sua correta identificação e a manutenção da cadeia de custódia. As zaragatoas e os cartões para manchas de sangue devem ser devidamente identificados com o nome do interveniente do processo e o seu grau ou pretenso grau de parentesco genético (ex.: pretenso pai, mãe, avó materna, etc...), a data e hora da recoIha e a assinatura do responsável pela mesma. Se possível, o número de processo também deve ser identificado. 
Durante a recolha das amostras é de evitar a contaminação destas com outro material biológico. Para tal é aconselhado o uso de material descartável, como luvas de latex, tendo o cuidado de as mudar para a colheita de diferentes indivíduos.

Apesar da recolha das amostras propriamente dita ser uma operação muito simples, existem sempre algumas precauções que devem ser levadas em conta. A recolha de saliva é realizada pela passagem da zaragatoa bucal na parte lateral da cavidade bucal, sendo a zaragatoa pressionada, num movimento alternado de cima para baixo, entre 6 a 8 vezes, em cada um dos lados da cavidade bucal.

A recolha de amostra de sangue faz-se, normalmente, com recurso a punção digital, usando uma lanceta apropriada para o efeito, sendo depositada uma mancha de sangue em papel Whatman, especificamente desenvolvido para esse efeito. No caso de menores, até um ano de idade, a punção digital deve ser substituída pela punção da superfície plantar lateral ou medial do calcanhar, por esta ser uma área de menor risco para a criança.

Caso exista necessidade de preparar o transporte de amostras de referência, para enviá-las do ponto de recolha para o laboratório onde irá decorrer a análise, as amostras deverão ser mantidas em ambiente seco e se possível, frio, devendo ser enviadas com a maior brevidade possível.

\section{SISTEMA DE GESTÃO DA QUALIDADE}

Conscientes da necessidade de constante implementação de medidas destinadas a garantir e a melhorar a qualidade das suas atividades, a maioria dos Laboratórios Forenses considera importante a comprovação da sua competência por uma terceira parte e de acordo com normas internacionais de referência, ou seja, a acreditação dos seus ensaios.

Esta decisão decorre do Council Framework Decision 2009/905/JHA, de 30 de Novembro de 2009, que estabelece a necessidade de acreditação dos serviços forenses que procedem a atividades laboratoriais. A acreditação deverá ser realizada pelo respetivo organismo nacional de acreditação, em Portugal, o Instituto Português de Acreditação, I.P. (IPAC).

O reconhecimento do impacto que os serviços prestados, pelos Laboratórios Forenses, tem para a Sociedade, em geral, encontra-se expresso na Decisão de 2009, que estabeleceu a obrigatoriedade, até 30 de Novembro de 2013, dos Laboratórios de Genética Forense da União Europeia procederem à acreditação dos ensaios de determinação de perfis de ADN.

Para a implementação da acreditação, os Laboratórios de Genética Forense, nomeadamente os Serviços de Genética e Biologia Forense do INML, I.P., entre outros, avançaram para a implementação de um Sistema de Gestão da Qualidade (SGQ), baseado na norma ISO/IEC 17025, com o qual se pretende assegurar a qualidade das atividades desenvolvidas e o cumprimento da legislação aplicável na área da Genética Forense. Este sistema apoia-se, entre outros, num conjunto de documentos, com os quais os Serviços documentam e organizam as suas atividades, baseando-se, quer nos mais recentes desenvolvimentos do conhecimento científico, quer na validação interna e externa (internacional) das metodologias usadas nos ensaios. 
Existem cuidados específicos que devem ser tidos não só na realização dos exercícios interlaboratoriais mas, principalmente, na resolução de casos reais, tais como a determinação dos perfis genéticos em duplicado e a utilização de mais do que um sistema multiplex para a determinação de um perfil de ADN. Pretende-se, deste modo, um processo de segurança com o objetivo de impedir uma troca de amostras, a incorreta determinação de perfis genéticos a partir destas, um erro no próprio ensaio ou na transcrição dos seus resultados.

Como referido anteriormente, aquando da colheita de amostras de referência, nos casos de investigação biológica de parentesco, são, normalmente, colhidas duas amostras de natureza diferente. Estas serão, posteriormente, analisadas por dois técnicos diferentes, de modo a garantir que as amostras não sofram qualquer troca.

A norma 17025 impõe, também, participação internacional em exercícios interlaboratoriais, com os quais se pretende conhecer a capacidade do Laboratório para a resolução de determinado tipo de ensaio. Embora seja relativamente recente a decisão da União Europeia acerca da obrigatoriedade da adoção da norma ISO/IEC 17025 pelos Laboratórios Forenses, já desde 2002, que a Comissão de Testes de Paternidade da Sociedade Internacional de Genética Forense recomenda a adoção desta por parte dos laboratórios que fazem este tipo de perícias (Morling et al., 2002).

Também por isso, desde há alguns anos, que vários grupos de trabalho da Sociedade Internacional de Genética Forense, sendo de destacar o Grupo de Línguas Espanhola e Portuguesa (GHEP) e o Grupo de Trabalho de Língua Inglesa (ESWG), têm promovido, anualmente, a realização de exercícios interlaboratoriais, os quais incluem uma prova de investigação de parentesco biológico, normalmente de maior complexidade que o simples caso envolvendo o trio p.pai/mãe/filho(a) (Hallenberg et al., 2001; Thomsen et al., 2009; Friis et al., 2009)

Nestes exercícios são testados, não só a capacidade técnica dos laboratórios na produção dos respetivos perfis genéticos dos indivíduos envolvidos, mas também a capacidade científica na resolução dos exercícios, pela determinação das relações de parentesco envolvidas e do cálculo das probabilidades de estas serem ou não verdadeiras.

Com esta atuação, os Laboratórios de Genética Forense conseguem garantir a manutenção das suas capacidades técnicas e científicas, bem como a qualidade dos ensaios e dos resultados apresentados nas perícias efetuadas.

\section{PERSPETIVAS FUTURAS}

O estudo do Genoma Humano, aprofundado pelos Projetos de Sequenciação, iniciados nos finais do século passado, permitiu a descoberta de novos marcadores genéticos de pequenas dimensões, mas com elevado potencial para diversas áreas da Genética (Venter et al., 2001), nomeadamente para a área forense.

De entre estes, os polimorfismos INDELs (de INsertion/DELetion, também designados por DIPs de Deletion Insertion Polimorphisms), mas, em especial, os SNPs (de Single Nucleotide Polymorphisms, polimorfismos de um único nucleótido), representam a classe mais abundante de polimorfismos humanos e têm sido alvo de um elevado número 
de estudos. Para se perceber como estes marcadores são abundantes, foi inicialmente estimada a ocorrência de 1 SNP por cada 1000pb do genoma humano (Venter et al., 2001). Contudo, na base de dados de SNPs dbSNP, pode verificar-se que já se encontram descritos cerca de 20 milhões de SNPs, 18 milhões dos quais validados, número que, a ser validado, indica a possibilidade da existência de um SNP por cada 150pb (Phillips, 2009).

Estes marcadores genéticos, para além de serem muito abundantes no genoma, permitem facilidade na análise, pelo facto de, na sua grande maioria, serem marcadores bialélicos, isto é, possuírem apenas dois alelos. Tal acontece porque a sua taxa de mutação é muitíssimo baixa $\left(10^{-8}\right.$ vs. $10^{-3}$ nos STRs), sendo, em média, no caso dos SNPs, de uma mutação por cada 100 milhões de gerações (Butler, 2005). Assim, é extremamente improvável que duas mutações pontuais ocorram numa mesma posição.

Esta característica torna-os muito úteis na análise de casos em que existam incompatibilidades genéticas nos sistemas STRs autossómicos e em casos envolvendo indivíduos que não se encontram geneticamente próximos, como nos trios p.pai/mãe/filho. Quanto mais afastados geneticamente estiverem os indivíduos em estudo, maior será a probabilidade de terem ocorrido mutações nos sistemas STRs estudados, dando origem a incompatibilidades genéticas entre indivíduos. Estas incompatibilidades, a somarem ao já de si pequeno número de alelos partilhados entre indivíduos geneticamente afastados, pode dificultar a resolução do caso, tornando-o mesmo inconclusivo. A análise dos SNPs permitirá a obtenção de informação genética adicional.

Todavia, o facto de estes marcadores apresentarem uma baixa taxa de mutação, é também responsável pela sua principal desvantagem relativamente aos STRs: são pouco polimórficos! Deste modo, para obter o poder discriminativo de 10-15 loci STR, para serem usados, por rotina, a nível laboratorial em investigação forense, serão necessários cerca de 50 a 100 SNPs com segregação independente, isto é, sem fenómenos de linkage (Gill, 2001; Amorim et al., 2005).

Em 2003, foi criado o Consórcio Internacional — SNPforID - com o objetivo de estudar e avaliar o uso de cerca de 50 loci SNP para análise forense, os quais teriam um poder de discriminação próximo dos 13 STRs do CODIS. Este Consórcio desenvolveu um multiplex de 52 SNPs (Sanchez et al., 2006), baseado na tecnologia SNaPshot, tendo sido validado para uso forense (Musgrave-Brown et al., 2007). Com base neste multiplex, foram efetuados vários estudos, quer com a totalidade dos 52 SNPs, quer apenas com alguns SNPs, verificando-se a utilidade destes na resolução de simples casos de paternidade, assim como em casos mais complexos (Ballard et al., 2009; Borsting et al., 2011; Borsting et al., 2008; Dario et al., 2009; Dario et al., 2011a; Dario et al., 2011b).

Também os INDELs demonstraram ser úteis na investigação de parentesco biológico (Friis et al., 2011; Neuvonen et al., 2011; Manta et al., 2012; Zidkova et al., 2011; Pereira et al., 2012), tendo para isso contribuído o multiplex Investigator DIPplex, recentemente comercializado, para determinação de um perfil genético destes marcadores (Pereira et al., 2009).

Os INDELs permitem a obtenção de fragmentos de ADN mais pequenos que os obtidos pela amplificação de loci STR, possibilitando melhores resultados a partir de amostras degradadas, como, por exemplo, de restos cadavéricos (Manta et al., 
2012; Romanini et al.), que, devido ao estado de degradação, podem não permitir a obtenção de um perfil genético de STRs para estudos de parentesco.

Contudo, o principal obstáculo à implementação da análise de marcadores bialélicos, na rotina forense, prende-se com o limitado número de marcadores possíveis de serem analisados, simultaneamente, com a tecnologia existente nos laboratórios, pois esta tecnologia permite a análise simultânea de poucas dezenas de SNPs, dificilmente ultrapassando a meia centena de marcadores, devido a questões técnicas.

Todavia, os SNPs podem ser analisados através de uma grande variedade de tecnologias de processamento em larga escala, com análise de dados automatizada, de dezenas, centenas, ou mesmo milhares destes marcadores, fornecendo um elevado poder de informação para análise genética, o que seria muito útil na investigação de parentesco biológico. Como exemplos, referem-se os equipamentos de Microarrays (microchips) e de espectroscopia de massa MALDITOF (Matrix Assisted Laser Desorption/ Ionization Time-Of-Flight).

Foi já realizado um estudo sobre o uso de SNPs, analisados com microchips de ADN, na investigação de um caso muito complexo de parentesco biológico, nomeadamente, na investigação de presumíveis primos em segundo grau (Lareu et al.). Este tipo de investigação, por recorrer a um elevado número de marcadores, dificilmente poderia ser realizado apenas através da análise de STRs, mesmo conjuntamente com os multiplex de SNPs e INDELs analisados por eletroforese capilar. Estas tecnologias dificilmente serão implementadas nos laboratórios forenses, pelo facto de serem tecnologias muito dispendiosas.
Por outro lado, o surgimento das novas tecnologias de sequenciação NGS (Next Generation Sequence) de segunda e terceira geração, de que são exemplos o 454 e o ION Torrent, respetivamente, permitem uma rápida sequenciação de grandes segmentos do genoma humano ou da sua totalidade, a custos cada vez menores. Deste modo, permitem a rápida determinação de um grande número de loci SNP, a partir dos quais se poderá obter um aumento no poder de análise genética nos casos de investigação biológica de parentesco (Berglund et al., 2011).

Porém, existem ainda problemas que terão de ser ultrapassados para a utilização destas tecnologias, nomeadamente os problemas de análise estatística e informática, derivados de fenómenos de linkage entre SNPs que se encontrem próximos e os problemas tecnológicos e computacionais derivados da grande quantidade de ADN a analisar e da ainda elevada taxa de erro na leitura da sequenciação do ADN (Berglund et al., 2011).

Apesar dos SNPs e dos INDELs não virem a substituir os STRs, pelo menos nos tempos mais próximos, estes marcadores, assim como as tecnologias desenvolvidas nos últimos anos para a sua deteção e análise, poderão vir a desempenhar, no futuro, um papel fundamental nas perícias mais complexas de investigação biológica de parentesco.

\section{CONCLUSÃO}

As perícias de investigação biológica de paternidade, no caso dos trios p.pai/mãe/filho(a), são realizadas nos Laboratórios de Genética Forense, essencialmente, através do estudo de 15 ou 17 
STRs pelos sistemas PowerPlex® 16 (/HS) System e/ou AmpFlSTR® Identifiler® (/Direct/Plus).

Embora estes sejam os casos mais comuns, são, também, solicitadas investigações biológicas de paternidade em casos com dois ou mais pretensos pais, ou com dois ou mais pretensos filhos, sendo que, também nestes casos, a base de estudo será sempre o trio p.pai/mãe/filho(a).

Mas nem sempre há a possibilidade do estudo de um trio, pelo que as investigações serão de casos incompletos, o que muitas vezes torna os casos bastante mais complexos. Nestas situações, recorre-se à investigação de paternidade com familiares do pretenso pai, o que levará ao estudo dos pretensos avós, de pretensos tios ou de filhos do pretenso pai, com possibilidade ou não do estudo das respetivas mães.

Mas a realidade com que o Laboratório se depara, por vezes, é bastante complexa, e embora dispondo de tecnologia adequada para as investigações biológicas de parentesco, pode ser necessário proceder a novas avaliações dos dados familiares fornecidos ao Laboratório. Em certas situações, por impossibilidade de estudo dos familiares do pretenso pai falecido, pode, por ordem do Tribunal, ter de se proceder à exumação do cadáver para recolha de material biológico disponível (ossos, dentes), de modo a realizar uma investigação de paternidade direta.

Embora os 17 STRs autossómicos sejam os marcadores, por excelência, para este tipo de investigações, por vezes, em casos mais complexos, pode ser necessário aumentar o número destes marcadores, recorrendo a outros sistemas multiplex utilizados nas perícias forenses - AmpFeSTR $®$ $\mathrm{NGM}^{\mathrm{TM}}$, um multiplex de nova geração, complementado com o sistema PowerPlex® SE.
Por outro lado, todos os Laboratórios de Genética Forense possuem idêntica tecnologia, necessária para o estudo daqueles marcadores, o que facilitará o intercâmbio de dados do ponto de vista nacional e internacional, mesmo neste tipo de investigações.

Porém, podem, também, ser utilizados, em investigações biológicas de parentesco mais complexas, outros marcadores genéticos. Consoante o caso, pode recorrer-se ao estudo de Y-STRs para estabelecimento da linha paterna, ao estudo de ADN mitocondrial no caso de ser necessário o estabelecimento da linha materna ou, em casos especiais, ao estudo dos STRs do cromossoma $X$, que são passados intactos de pais para filhas, podendo, assim, estabelecer-se uma hipótese de relação de irmandade.

Os SNPs autossómicos que usam a tecnologia de sequenciação e determinação de perfis de STRs, são os marcadores que, atualmente, começam a ser utilizados, com muito êxito na prática forense, assim como o estudo de INDELs, para complementar investigações complexas de parentesco.

Têm, também, sido implementadas bases de dados populacionais de perfis genéticos de STRS para estudo das respetivas frequências alélicas, a aplicar nos cálculos estatísticos realizados através do programa Familias, considerando a dinâmica populacional do respetivo Laboratório, que varia, consoante o fluxo populacional imergente e emergente, que se vai estabelecendo a nível das diversas Comunidades.

O surgimento das novas tecnologias de sequenciação NGS (Next Generation Sequence) de segunda e terceira geração, como o 454 e o ION Torrent, respetivamente, irão permitir uma 
rápida sequenciação de grandes segmentos do genoma humano, a custos cada vez menores, o que contribuirá para aumentar o poder de análise genética nos casos de investigação biológica de parentesco.

\section{BIBLIOGRAFIA}

Amorim, A. e Pereira, L. (2005). Pros and cons in the use of SNPs in forensic kinship investigation: a comparative analysis with STRs. Forensic science international 150 (1), 17-21.

Ballard, D. J., Musgrave-Brown, E., Khan, L., Harrison, C., Phillips, C., Thacker, C. R. e Court, D. S. (2009). Supplementary markers for deficient immigration cases: Additional STRs or SNPs? Forensic Science International: Genetics Supplement Series 2 (1), 153-154.

Berglund, E. C., Kiialainen, A. e Syvanen, A. C. (2011). Nextgeneration sequencing technologies and applications for human genetic history and forensics. Investigative Genetics, 2, 23.

Borsting, C. e Morling, N. (2011). Mutations and/or close relatives? Six case work examples where 49 autosomal SNPs were used as supplementary markers. Forensic Science International: Genetics 5 (3), 236-241.

Borsting, C., Sanchez, J. J., Hansen, H. E., Hansen, A. J., Bruun, H. Q. e Morling, N. (2008). Performance of the SNPforID 52 SNP-plex assay in paternity testing. Forensic Science International: Genetics, 2 (4), 292-300.

Butler, J. M. 2005. Forensic DNA Typing - Biology, Technology, and Genetics of STR Markers: Elsevier Academic Press.

Código Civil Português. Diário da República.

Dario, P., Ribeiro, T., Dias, D., Corte-Real, F. e Geada, H. (2011a). Complex casework using single nucleotide polymorphisms. Forensic Science International: Genetics Supplement Series, 3 (1), e379-e380.

Dario, P., Ribeiro, T., Espinheira, R. e Geada, H. (2009). SNPs in paternity investigation: The simple future. Forensic Science International: Genetics Supplement Series, 2 (1), 127-128.
Dario, P., Ribeiro, T., Espinheira, R., Dias, D., Geada, H. e Corte-Real, F. (2011b). 20 SNPs as supplementary markers in kinship testing. Forensic Science International: Genetics Supplement Series 3 (1), e508-e509.

Egeland, T., Mostad, P. F., Mevag, B. e Stenersen, M. (2000). Beyond traditional paternity and identification cases. Selecting the most probable pedigree. Forensic science international, 110 (1), 47-59.

Friis, S. L., Borsting, C., Rockenbauer, E., Poulsen, L., Fredslund, S. F., Tomas, C. e Morling, N. (2011). Typing of 30 insertion/deletions in Danes using the first commercial indel kit-Mentype((R)) DIPplex. Forensic Science International: Genetics.

Friis, S. L., Hallenberg, C., Simonsen, B. T. e Morling, N. (2009). Results of the 2009 Paternity Testing Workshop of the English Speaking Working Group of the International Society for Forensic Genetics. Forensic Science International: Genetics Supplement Series 2, 91-92.

Geada, H. e Flores, M. (1990-91). Exames de Sangue e Estabelecimento da Paternidade. Textos. Centro de Estudos Judiciários.

Geada, H., Ribeiro, T., Brito, R. M., Espinheira, R., Rolf, B., Hohoff, C. e Brinkmann, B. (2001). A STR mutation in a heteropaternal twin case. Forensic science international, $123(2-3), 239-242$.

Gill, P. (2001). An assessment of the utility of single nucleotide polymorphisms (SNPs) for forensic purposes. International Journal of Legal Medicine 114 (4-5), 204-210.

Gjertson, D. W., Brenner, C. H., Baur, M. P., Carracedo, A., Guidet, F., Luque, J. a., Lessig, R., Mayr, W. R., Pascali, V. L., Prinz, M. et al. . (2007). ISFG: Recommendations on biostatistics in paternity testing. Forensic Science International: Genetics, 1, 223-231.

Hallenberg, C. e Morling, N. (2001). A report of the 1997, 1998 and 1999 paternity testing workshops of the English Speaking Working Group of the International Society for Forensic Genetics. Forensic science international, 116, 23-33.

Jeffreys, A. J., Brookfield, J. F. e Semeonoff, R. (1985). Positive identification of an immigration test-case using human DNA fingerprints. Nature, 317 (6040), 818-819.

Landsteiner, K. e Levine, P. (1928). On individual differences in human blood. Journal of Experimental Medicine, 47 (5), 757-775. 
Lareu, M. V., García-Magariños, M., Phillips, C., Quintela, I., Carracedo, Á. e Salas, A. Analysis of a claimed distant relationship in a deficient pedigree using high density SNP data. Forensic Science International: Genetics (em impressão).

Manta, F., Caiafa, A., Pereira, R., Silva, D., Amorim, A., Carvalho, E. F. e Gusmao, L. (2012). Indel markers: Genetic diversity of 38 polymorphisms in Brazilian populations and application in a paternity investigation with post mortem material. Forensic Science International: Genetics.

Morling, N., Allen, R., Carracedo, A., Geada, H., Guidet, F., Hallenberg, C., Martin, W., Mayr, W. R., Olaisen, B., Pascali, V. et al. . (2002). Paternity Testing Commission of the International Society of Forensic Genetics. Recommendations on genetic investigations in paternity cases. Forensic science international, 129, 148-157.

Musgrave-Brown, E., Ballard, D., Balogh, K., Bender, K., Berger, B., Bogus, M., Borsting, C., Brion, M., Fondevila, M., Harrison, C. et al. . (2007). Forensic validation of the SNPforID 52-plex assay. Forensic Science International: Genetics, 1 (2), 186-190.

Neuvonen, A. M., Palo, J. U., Hedman, M. e Sajantila, A. (2011). Discrimination power of Investigator DIPplex loci in Finnish and Somali populations. Forensic Science International: Genetics.

Oliveira, G. d. (1983). Critério Jurídico da Paternidade (Tese de Doutoramento). Coimbra: Universidade de Coimbra.

Pereira, R. e Gusmao, L. (2012). Capillary electrophoresis of 38 noncoding biallelic mini-Indels for degraded samples and as complementary tool in paternity testing. Methods in Molecular Biology, 830, 141-157.

Pereira, R., Phillips, C., Alves, C., Amorim, A., Carracedo, A. e Gusmao, L. (2009). A new multiplex for human identification using insertion/deletion polymorphisms. Electrophoresis, 30 (21), 3682-3690.

Phillips, C. (2009). SNP databases. In Komar, A. A., (Ed.), Methods in Molecular Biology. (pp. 43-71). Clifton, N.J.: Wiley Online Library.

Romanini, C., Catelli, M. L., Borosky, A., Pereira, R., Romero, M., Salado Puerto, M., Phillips, C., Fondevila, M., Freire, A., Santos, C. et al. . Typing short amplicon binary polymorphisms: Supplementary SNP and Indel genetic information in the analysis of highly degraded skeletal remains. Forensic Science International: Genetics (em impressão).
Sanchez, J. J., Phillips, C., Borsting, C., Balogh, K., Bogus, M., Fondevila, M., Harrison, C. D., Musgrave-Brown, E., Salas, A., Syndercombe-Court, D. et al. . (2006). A multiplex assay with 52 single nucleotide polymorphisms for human identification. Electrophoresis 27 (9), 1713-1724.

Santos, H. G., Pereira, A. G. D. e Vieira, L. M. (2010). Normas de bioética e questões jurídicas na realização de testes de paternidade fora de um processo judicial em Portugal Parecer da Comissão de Bioética da Sociedade Portuguesa de Genética Humana (SPGH).

Thomsen, A. R., Hallenberg, C., Simonsen, B. T., Langkjaer, R. B. e Morling, N. (2009). A report of the 2002-2008 paternity testing workshops of the English speaking working group of the International Society for Forensic Genetics. Forensic Science International: Genetics, 3, 214-221.

Venter, J. C., Adams, M. D., Myers, E. W., Li, P. W., Mural, R. J., Sutton, G. G., Smith, H. O., Yandell, M., Evans, C. A., Holt, R. A. et al. . (2001). The sequence of the human genome. Science 291 (5507): 1304-1351.

Zidkova, A., Horinek, A., Kebrdlova, V. e Korabecna, M. (2011). Application of the new insertion-deletion polymorphism kit for forensic identification and parentage testing on the Czech population. International Journal of Legal Medicine (em impressão). 